\title{
RMetS
}

Royal Meteorological Society

\section{Short-wave and long-wave radiative properties of Saharan dust aerosol}

\author{
S. R. Osborne $\mathrm{a}^{\mathrm{a} \dagger}$, A. J. Baran ${ }^{\mathrm{a} \dagger}$, B. T. Johnson ${ }^{\mathrm{a} \dagger}$, J. M. Haywood ${ }^{\mathrm{a} \dagger}$, E. Hesse ${ }^{\mathrm{b}}$ and S. \\ Newman ${ }^{\mathrm{a} \dagger}$ \\ ${ }^{a}$ Met Office, Exeter, UK \\ ${ }^{\mathrm{b}}$ University of Hertfordshire, Hatfield, UK \\ ${ }^{*}$ Correspondence to: S. R. Osborne, Met Office Field Site, Cardington Airfield, Shortstown, \\ Bedford MK42 0SY, UK. E-mail: simon.osborne@metoffice.gov.uk \\ ${ }^{\dagger}$ The contributions of these authors were written in the course of their employment at the Met Office, UK, and are \\ published with the permission of the Controller of HMSO and the Queen's Printer for Scotland.
}

The radiative properties of mineral dust aerosol during the GERB Intercomparison of Long-wave and Short-wave (GERBILS) are presented. GERBILS consisted of aircraft flights over land areas between Mauritania and Niger during June 2007. During one case of large aerosol optical depth $(\mathrm{AOD}=1.0$ at $0.55 \mu \mathrm{m})$, a short-wave spectrometer measured sky radiances versus scattering angle that are compared to modelled data. The modelling used phase functions of spheres, spheroids and irregular-shaped particles using T-matrix and ray-tracing methods. Irregular particles provided the most satisfactory solution. In another case of full short-wave and long-wave radiative closure, measurements and modelled clear sky conditions allowed calculation of the direct radiative effect (DRE) at high and low level. The modelled AOD (0.92) required to simulate the measured spectral irradiances agrees with the aircraft AOD (0.79) within measurement uncertainty. The simulated irradiances are less sensitive to particle shape than radiances. However, it is shown through modelling of the surface and top-of-atmosphere (TOA) DRE over all daylight hours that significant differences exist at TOA due to variation in the asymmetry parameter. The TOA short-wave diurnally averaged DRE was modelled as between 0 and $-20 \mathrm{~W} \mathrm{~m}^{-2}$ depending on particle shape. A long-wave interferometer measured downwelling and upwelling radiances to derive surface emissivity across the window region. Measured nadir brightness temperatures from high level show signature of dust. A drop in brightness temperature of $14 \mathrm{~K}$ was determined using modelled pristine-sky spectra. The modelled outgoing long-wave DRE due to dust from this case was $+14 \mathrm{~W} \mathrm{~m}^{-2}$ averaged over $24 \mathrm{~h}$, or $+17 \mathrm{~W} \mathrm{~m}^{-2}$ per unit AOD. Modelling studies illustrate the sensitivity to aerosol refractive index and size distribution for both short-wave and long-wave DREs. Considering the full spectrum, a refractive index dataset from the literature has been selected that best represents the Saharan dust encountered during GERBILS. Copyright (c) 2011 Royal Meteorological Society and British Crown Copyright, the Met Office

Key Words: aircraft measurements; sky radiance; phase function; non-spherical particles; direct radiative effect; brightness temperature

Received 14 July 2010; Revised 1 December 2010; Accepted 13 December 2010; Published online in Wiley Online Library 7 March 2011

Citation: Osborne SR, Baran AJ, Johnson BT, Haywood JM, Hesse E, Newman S. 2011. Short-wave and long-wave radiative properties of Saharan dust aerosol. Q. J. R. Meteorol. Soc. 137: 1149-1167. DOI:10.1002/qj.771 


\section{Introduction}

Mineral dust aerosol is an important component of atmospheric aerosol because of its effect on radiative forcing (Forster et al., 2007), its contribution to atmospheric chemistry (De Reus et al., 2005), and its transport and deposition of iron to the ocean (McConnell et al., 2008). The complex refractive index of the parent material can vary measurably between source regions such as the Sahara and the Sahel (Formenti et al., 2008; Petzold et al., 2009). The spectral refractive index depends on the types of iron oxide and clays present, and their mass fraction (Sokolik and Toon, 1999; Lafon et al., 2006). Once airborne, the total optical properties of the dust aerosol, such as single scattering albedo (SSA) and asymmetry parameter, depend on aerosol mixing state, i.e. whether internal or external (McConnell et al., 2010), particle morphology (Otto et al., 2009) and size distribution. The latter is a strong function of dust plume age whereby larger particles are lost through sedimentation and hence have an effect on the column radiative properties (Dubovik et al., 2002).

Due to the strong contribution of coarse mode particles, mineral dust aerosol is an efficient absorber and emitter of terrestrial radiation and can therefore act in an analagous manner to a greenhouse gas that produces a net reduction in outgoing thermal radiation (Highwood et al., 2003). The significance of a dust coarse mode of highly variable magnitude and mode radius makes representative measurement from aircraft a particular challenge: there is the double problem of aerosol inlet efficiency for super-micron particles (Wendisch et al., 2004) and sizing of non-spherical particles using optical instruments (Osborne et al., 2004). The subject of the dust coarse mode in situ measurement for the present experiment is covered by Johnson and Osborne (2011). The sensitivity of radiative properties to errors in the coarse mode are addressed below.

Direct radiative effects (DRE) of a column of dust are divided into broad-band short-wave (solar) and long-wave (thermal) spectra. The value of dust DRE depends on the optical properties of the dust (SSA, asymmetry parameter, specific extinction coefficient), the vertical profile of the aerosol layer, the position of the sun, the underlying surface albedo, and presence of clouds (Quijano et al., 2000). All our work below pertains to cloud-free atmospheres. The surface spectral albedo, whether ocean, land or cloud, plays a important role in determining the magnitude and sign of the short-wave DRE. For a given surface albedo, there will be a critical level of optical absorption (usually determined as the SSA) at which the sign of the top-of-atmosphere (TOA) DRE changes from negative to positive (Haywood and Boucher, 2000). Most studies of regional dust short-wave DRE show a negative value (cooling) over a dark ocean surface with values between about zero and $-130 \mathrm{~W} \mathrm{~m}^{-2}$ (Bierwirth et al., 2009). However, Deepshikha et al. (2006) show that a small positive TOA DRE $\left(4.5 \mathrm{~W} \mathrm{~m}^{-2}\right)$ is possible over ocean where the dust is particularly absorbing ( $S S A=0.82)$. A modelling study based on in situ aircraft data by Otto et al. (2007) showed that, for a solar zenith angle set to zero, the TOA short-wave DRE for aerosol optical depth $(\mathrm{AOD})=1.0$ (at $0.55 \mu \mathrm{m})$ was $-16 \mathrm{~W} \mathrm{~m}^{-2}$ over ocean, and $+37 \mathrm{~W} \mathrm{~m}^{-2}$ over desert. Quijano et al. (2000) show that the short-wave TOA DRE over ocean was about $-45 \mathrm{~W} \mathrm{~m}^{-2}$ for $\mathrm{AOD}=1.0$ (at $0.55 \mu \mathrm{m}$ ) and a solar zenith angle of $75^{\circ}$. Over a desert surface, the value was about $+50 \mathrm{~W} \mathrm{~m}^{-2}$ for a solar zenith angle of $37^{\circ}$. Dependency of DRE on solar position (time of day) is analysed in this study.

Kahnert et al. (2007) have shown that the assumption of dust particles as spheres can lead to errors of similar magnitude to the uncertainty in the refractive index when calculating short-wave radiative forcing at the surface and at the TOA. The review paper by Nousiainen (2009) states that Mie-Lorenz theory should be avoided when dealing with the optical properties of dust particles, demonstrating that the assumption of smooth homogenous spheroids generally performs well. Particle shape scattering errors can affect not only radiances but radiative fluxes too and hence the radiative balance of the atmosphere (Kalashnikova and Sokolik, 2004; Kahnert et al., 2007). Kahnert et al. (2007) show that the error in simulated TOA net flux approaches $10 \%$ of the incoming solar flux caused by using a spherical dust phase function as opposed to using a phase function of Saharan dust determined in the laboratory.

The application of randomised mixtures of spheroids to represent the scattering properties of mineral dust has been used with some level of success by many authors. Dubovik et al. (2006) show, in regard to AERONET sunphotometer measurements of downwelling sky radiances, an improvement of spheroids over spheres demonstrated using simulations for a case-study of mineral dust of moderate AOD $(\approx 0.5)$. Good agreement of scattered radiances was found between measurements and spheroid modelling at visible and near-infrared wavelengths and across all scattering angles (up to $140^{\circ}$ ). A distribution of spheroid aspect ratios was used in the Dubovik et al. (2006) scheme. The assumption of spheroid particles having aspect ratios of 1.6 was sufficient by Otto et al. (2009) to explain groundbased lidar and sun-photometer measurements during Saharan dust events. The SSA of the dust changed by only $1 \%$ between spheres and spheroids, and the asymmetry parameter only changed by $4 \%$. But the effect of spheroids can lead to short-wave radiative effects at TOA of $29 \%$ over a desert surface, i.e. the non-sphericity acts to cool the atmosphere over a bright surface. Below we examine the modelled effect of spheres, a mixture of spheroids, and also irregular-shape particles containing sharp edges, on short-wave radiances and irradiances.

Dust detection from space has been possible over land and sea surfaces since the 1970s (e.g. Shenk and Curran, 1974). Such studies have used information within the thermal window region of the spectrum. The sensitivity to the dust (i.e. reduction in nadir brightness temperature) is greatest around local noon when the surface temperature is much greater than the near-surface air temperature. Many subsequent satellite and modelling studies have been based on data taken at noon to determine peak perturbations to the outgoing long-wave radiation. Regional long-wave DREs in the literature are commonly positive (warming) both at the surface and TOA, regardless of whether the dust is over a land or ocean surface (Bierwirth et al., 2009). The magnitude of the long-wave DRE is proportional to the surface skin temperature and to the height of the aerosol layer, and is inverserly proportional to the water vapour content (Zhang and Christopher, 2003). Brindley (2007) showed using Meteosat-8 data (Geostationary Earth Radiation Budget (GERB) and the Spinning Enhanced Visible and Infrared Imager (SEVIRI)) that the March-June 2006 midday mean long-wave forcing due to dust aerosols over a site in Niger was $17 \pm 5 \mathrm{~W} \mathrm{~m}^{-2}$ per unit AOD (at $0.67 \mu \mathrm{m}$ ). Zhang and 
Christoper (2003) show, using combined MISR/CERES satellite data, that the mean long-wave dust forcing averaged over the domain of the Sahara desert for September 2000 was $15 \mathrm{~W} \mathrm{~m}^{-2}$ per unit AOD (at $0.55 \mu \mathrm{m}$ ). Peak midday perturbations in the outgoing long-wave radiation during a huge dust storm in March 2006, described by Slingo et al. (2006), were about $30 \mathrm{~W} \mathrm{~m}^{-2}$. Although these data represent case-studies of events which by their nature are sporadic, satellite data allows long-term dust climatologies to be developed of dust emission and transport (Legrand et al., 2001).

This paper presents radiometric aircraft observations collected during the Geostationary Earth Radiation Budget Intercomparisons of Long-Wave and Short-Wave radiation (GERBILS) field campaign over the Sahara desert in June 2007 (Haywood et al., 2011a). The measurements in essence consist of downwelling and upwelling long-wave and shortwave spectral radiances and irradiances that contain a signature due to mineral dust particles. Attempts to model the observed spectra are made by including theoretically generated aerosol phase functions constrained by the measured aerosol size distribution. The difference between measured spectra and modelled pristine-sky counterparts allow us to determine quantities such as the DRE above and below the dust layer. By this method, an understanding is sought of the effect the aerosol has on radiative transfer.

Haywood et al. (2005) showed using radiative transfer modelling that the bias between the Met Office numerical weather predictions of outgoing long-wave radiation and that shown by Meteosat-7 data over North Africa is probably due to the presence of dust aerosol. A monthly mean study from July 2003 showed that the model emits $35 \mathrm{~W} \mathrm{~m}^{-2}$ more long-wave radiation than that measured by Meteosat7. Modification of the transmission by airborne dust seemed the most likely candidate rather than errors in the surface temperature and surface emissivity, i.e. absorption of thermal radiation by dust aerosol and re-emission at a lower temperature relative to the ground. However, Haywood et al. (2005) carried out their modelling work using monthly mean sonde profiles and generic aircraft size distribution data. Analysis of individual case-studies is required if we are to solve this problem; this requirement was one of the principal reasons for conducting the GERBILS campaign (Haywood et al., 2011a). In this paper we analyse a longwave case-study using aircraft interferometer measurements and a radiative transfer band model.

Highwood et al. (2003) used interferometer measurements and modelling to analyse the effect of dust on the radiative transfer in the window region $(8-12 \mu \mathrm{m})$. One of the main focuses of this work was the sensitivity of brightness temperature (using both nadir and zenith views) to the aerosol refractive index. Refractive index was the main uncertainty in trying to model the long-wave radiances i.e. a range of published refractive indices produced greater variability than appreciable perturbations in any one of the following parameters: sea surface temperature, aerosol mass loading, vertical temperature profile and altitude of the dust layer.

A major problem with estimates of the short-wave and long-wave DRE of dust aerosol using satellite data and radiative transfer modelling is the lack of concurrent detailed information of the aerosol optical properties, atmospheric vertical structure and surface reflection properties. This can only be overcome by multi-disciplinary experiments such as the Dust and Biomass-burning Experiment (DABEX; Haywood et al., 2008a) and the Saharan Mineral Dust Experiment (SAUMUM; Heintzenberg, 2009) where significant improvements in our knowledge have occurred. The problem is also directly addressed here where novel measurements of short-wave radiances measured from an aircraft are included. Johnson and Osborne (2011) provide an overview of the aims of GERBILS and a summary of the in situ aerosol microphysics and total optical properties. Here we focus on flight B295 (19 June 2007) for the shortwave scattered sky radiance case-study, and flight B300 (25 June 2007) for a combined short-wave and long-wave case-study using a vertically aligned Z-pattern of high- and low-level runs. Both case-studies took place over land: B295 over Mali near the Niger border, and B300 over Mauritania near the Mali border. The flight patterns and other flight details are shown in Johnson and Osborne (2011). Haywood et al. (2011b) show a similar approach for a case-study over the sea and comparative results from the B295 case-study are highlighted below.

\section{Instrumentation}

Data have been gathered on the UK community BAe146 aircraft operated by the Facility for Atmospheric Airborne Measurements (FAAM; http://www.faam.ac.uk/). A general overview of instrumentation on the BAe-146 has been described previously by Highwood et al. (2007) and Haywood et al. (2008b). Johnson and Osborne (2011) describe the instrumentation used for measuring in situ aerosol properties such as the size distribution and scattering and absorption coefficients. Below we describe two new short-wave radiometers that were operated in GERBILS. This article, together with that of Haywood et al. (2011b), represents the first published analysis of data gathered with these instruments on the BAe-146 and so some moderate level of detail is necessary. Also briefly described below is the interferometer used for the long-wave spectral measurements.

\subsection{SWS}

The short-wave spectrometer (SWS) is a high-resolution radiometer with external viewing optics (constructed inhouse) mounted onto one of the cabin window positions. The external scanning telescope can view at any angle except for regions fore $\left(55-86^{\circ}\right)$ and aft $\left(61-75^{\circ}\right)$ which are obscured by the aircraft wing and tailplane. The scanner allows light to enter through two conical tubes, one for the visible module and one for the near-infrared module, that restrict the field of view to approximately $1.5^{\circ}$ half-angle. The internal surfaces of these tubes, and all other internal surfaces of the scanner, are painted black. At the base of these restrictors are windows made of synthetic fused silica that seal the evacuated scanner from the ambient atmosphere. Light passes through these windows, off a $45^{\circ}$ polished aluminium mirror and onto lenses, one for each of the two modules. The lens are also made of synthetic fused silica and they focus the light onto the entrance of fibre optic cables. These cables transmit the light into the aircraft cabin to the detector modules. Baffles surrounding each lens reduce stray internal reflections entering the fibre optics. Only the central portion of each lens is effectively used in order to minimise the effect of spherical and chromatic aberration. 


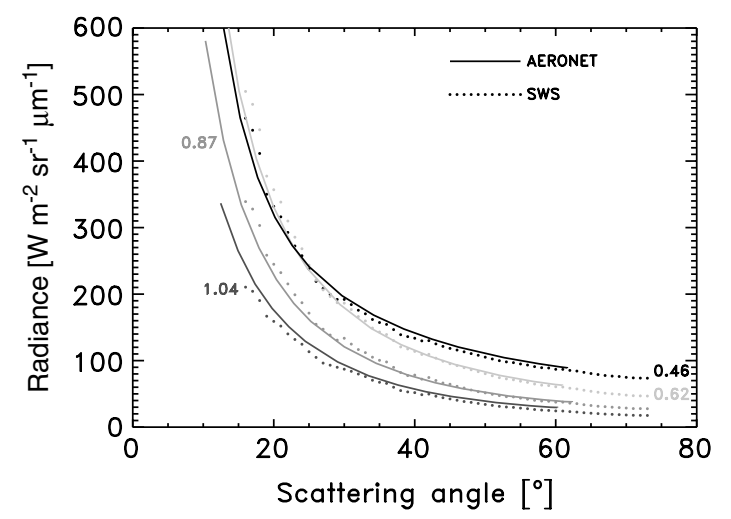

Figure 1. Comparison of SWS aircraft radiances measured during an orbit at an altitude of $150 \mathrm{~m}$ and Dakar AERONET almucantar scan radiances for four annotated AERONET radiances $(\mu \mathrm{m})$.

The vaccum of the scanner unit ensures that the high-quality aluminium mirror finish is maintained. The SWS uses two diffraction-grating detector modules manufactured by Carl Zeiss Inc., i.e. the short-wave $(302-1145 \mathrm{~nm})$ and nearinfrared (947-1706 nm) modules. The spectral resolution of the modules is about $3 \mathrm{~nm}$.

When the SWS is calibrated in the laboratory, the whole system (including the scanning telescope and fibre optics) is removed from the aircraft. The calibration source is a Labsphere CSTM-USS-2000S Uniform Source System and the calibration relevant to the data below took place shortly after the end of the GERBILS campaign. As a sanity check, we can compare in-flight SWS radiances on an opportunistic basis with those from ground-based radiometers that measure sky radiances at a range of fixed wavelengths to ensure that the SWS calibration was carried out satisfactorily. A horizontal aircraft orbit banked at a certain angle for a fixed SWS viewing angle (normally set to the zenith relative to the aircraft frame) performs a scan analogous to the almucantar scans of the ground-based CIMEL sun-and-sky scanning photometers that are part of the AERONET network (Holben et al., 1998). The angle of bank of the aircraft is usually set to $\approx 10^{\circ}$ greater than the solar zenith angle to allow a range of scattering angles (equal to twice the solar zenith angle) to be measured that are offset from the solar disc, i.e. the aircraft performs offsun almucantars to avoid the SWS signal saturating. During GERBILS flight B297, the aircraft performed an orbit at low-level (180 m altitude) near the Dakar AERONET site. The comparison between the radiances measured from the AERONET almucantar scan and the SWS radiances as a function of scattering angle are shown in Figure 1. These radiances are those transmitted through a layer of mineral dust aerosol having an AOD (at $0.55 \mu \mathrm{m}$ ) of about 0.7 . Both the magnitude and the wavelength dependence (for the four AERONET wavelengths available) compare very favourably. Such scattering diagrams, which depend much on the scattering phase function of the aerosol, are the concern of section 5 .

We believe that the SWS data shown here and also in section 5 represent the first airborne radiance measurements of their kind in atmospheric dust.

\subsection{SHIMS}

SHIMS (Spectral Hemispheric Irradiance Measurements) is an instrument that measures spectral irradiance using identical detector modules to the SWS, i.e. the wavelength ranges and resolution are equal to those quoted above for the SWS. There are two SHIMS units on the aircraft, mounted at lower and upper positions to measure upwelling and downwelling irradiances. The front-end optics of SHIMS was constructed in-house and consists of a $60 \mathrm{~mm}$ diameter hemispherical Eppley clear glass dome mounted over an aperture that allows very close to $180^{\circ}$ field of view. The horizontal surface external to the glass dome is painted in Nextel velvet black to minimise reflections onto and through the dome. Beneath the aperture is a Labsphere Spectralon integrating sphere that diffuses the incoming radiation via multiple internal reflections so that a small fraction of the incoming radiation hits the top of a fibre optic cable that takes the collected radiation to the detectors. A baffle is mounted within the integrating spheres to shield the optic fibre from direct radiation. The whole unit is evacuated to guarantee no internal moisture and to maintain the reflectivity of the barium sulphate paint that is used on some surfaces.

The upper and lower SHIMS raw counts were not calibrated by laboratory means but by using a radiation code (detailed below) to model the fluxes over the sea during flight B294. Haywood et al. (2011b) provide more details on this particular flight. During an aerosol-free straight and level run of this flight, modelled spectral fluxes were used as the 'correct' values and so a spectral correction could be applied to the SHIMS raw counts. The model was validated during this case-study by the very good agreement between the model and broad-band irradiance measurements as shown in Haywood et al. (2011b). The latter instruments are calibrated independently during ground trials against an international standard. The B294 SHIMS calibration was used for all of the GERBILS SHIMS dataset. Pitch and roll corrections have been applied to the upper SHIMS data to ensure the measurement represents the hemispherical radiation flux through a horizontal area element. The same corrections have not been applied to the lower SHIMS because it is much less sensitive to small variations in aircraft attitude during straight and level runs.

Although the SHIMS data below and in Haywood et al. (2011b) are the first published SHIMS data from the BAe146, airborne spectral irradiances over Morocco have been published previously by Bierwirth et al. (2009) to measure the surface spectral reflectance and to assess dust radiative forcing.

\subsection{ARIES}

Infrared spectral radiances were measured with the Airborne Research Interferometer Evaluation System (ARIES) as described by Wilson et al. (1999). ARIES is sensitive to radiation in the range $3.3-18 \mu \mathrm{m}\left(550-3000 \mathrm{~cm}^{-1}\right)$ and has a resolution of $0.482 \mathrm{~cm}^{-1}$. ARIES is located in a special blister mounted on the port side of the aircraft forward of the engines and is capable of measuring in the zenith and nadir (as well as various angular downward views). ARIES uses two internal black bodies as calibration targets, nominally called the hot and cold targets whose temperatures should straddle the scene temperature. Typically, a low-level run around midday during GERBILS indicated the cold black body to be $\approx 315 \mathrm{~K}$, the hot black body $\approx 345 \mathrm{~K}$, and the desert surface temperature $\approx 330 \mathrm{~K}$, allowing for a satisfactory two-point calibration necessary to process 
the raw spectral signal. The ARIES spectral radiances are converted into brightness temperatures by inversion of the Planck function. Individual ARIES spectra are subject to noise, which is about $0.2-0.4 \mathrm{~K}$ at $300 \mathrm{~K}$ scene temperature for the spectral region $700-1300 \mathrm{~cm}^{-1}$. However, averaging of data reduces this substantially, so random noise is not a large source of error. There is also the potential for calibration biases to arise as a result of non-unity emissivity of the ARIES black-body targets. However, laboratory tests have determined these errors are only large $(>1 \mathrm{~K})$ for very cold scenes $(<200 \mathrm{~K})$. For warmer scenes $(>270 \mathrm{~K})$, the biases are expected to be $<0.5 \mathrm{~K}$.

\section{Dust refractive index}

The real part of the dust refractive index is fairly well constrained in the literature with values between 1.51-1.56 at a wavelength of $0.55 \mu \mathrm{m}$. (McConnell et al., 2010). Values of the imaginary part, which determines the absorption, vary by more than one order of magnitude. Example Saharan dust values spanning this large range at a wavelength of $0.55 \mu \mathrm{m}$ are 0.008i (Shettle and Fenn, 1979), 0.006i (Patterson et al., 1977), 0.002i-0.004i (Petzold et al., 2009), 0.0015i (Haywood et al., 2003a), and 0.0004i (Osborne et al., 2008). A number of recent field campaigns that use photometer devices to measure the aerosol absorption coefficient (e.g. Osborne et al. 2008; Petzold et al., 2009) have shown that the imaginary part of the refractive index is lower than reported in the earlier literature. Much of the variability in the measured absorption (SSA) of mineral dust can be reconciled by the size of the coarse mode, whether this is real or a sampling artefact (Osborne et al., 2008). For a refractive index that is constant with particle size, a larger coarse mode results in a lower SSA.

The mineral dust encountered during GERBILS is assumed to possess the complex refractive index of Balkanski et al. (2007) for a moderate (1.5\%) volume mixture of hematite, the principal absorbing component of dust in the short-wave. The refractive index is assumed to be constant with particle size over our measurement range i.e. approximately $0.1-25 \mu \mathrm{m}$ radius. It is realized that this may be a source of significant error (Otto et al., 2009). The $1.5 \%$ hematite data was chosen over the other datasets (i.e. 0.9 and $2.7 \%$ hematite by volume) because the SSA at $0.55 \mu \mathrm{m}$ inferred from Mie-Lorenz and Tmatrix calculations was closest to the measured SSA of 0.97 (Johnson and Osborne, 2011). The imaginary part of the refractive index at $0.55 \mu \mathrm{m}$ is $0.00147 \mathrm{i}$, which is in good agreement with recent laboratory measurements of Moroccan dust collected during SAMUM indicating 0.00160 \pm 0.001 (Müller et al., 2009). In addition, the $1.5 \%$ hematite content is close to the mean value of $\approx 1.7 \%$ reported for GERBILS dust based on laboratory measurements of filter samples taken on board the BAe-146 (Klaver et al., 2011). Klaver et al. also computed a complex refractive index from their mineralogical data and the range was $0.001 \mathrm{i}-0.0027 \mathrm{i}$ for a wavelength of $0.55 \mu \mathrm{m}$. This encompasses the value of 0.00147i from Balkanksi et al. (2007). The choice of using Balkanksi et al. (2007) allowed us to use a single referenced refractive index dataset for broad-band and narrow-band calculations across both short-wave and long-wave spectra (see below).

Figure 2(a,b) show the variation of the Balkanski real and imaginary refractive indices for $0.9,1.5$ and $2.7 \%$ hematite content across the short-wave spectrum $(0.2-3.0 \mu \mathrm{m})$, together with the Volz (1973) dataset. The WMO (WCP, 1986) and Fouquart et al. (1987) datasets are similar to the Volz data in the short wave and so are not shown. At visible wavelengths the real part shows little variation between datasets. However, for the imaginary part, the Volz data are about a factor of five greater then the 1.5\% Balkanksi refractive index data at $0.55 \mu \mathrm{m}$. The SSA implied by the Volz data, using Mie-Lorenz computations, is far too low $(\mathrm{SSA} \approx 0.85)$ compared to the in situ measurements during GERBILS. The Balkanski refractive index 0.9 and $1.5 \%$ hematite data shows a difference of about $40 \%$ in the imaginary part of the refractive index. This difference is used in error assessments of modelled sky radiances (section 5) and the DRE (section 7.1).

For long-wave considerations in section 6.2 the Balksanki refractive index is used in comparison to the Volz (1973), WMO (WCP, 1986) and Fouquart et al. (1987) datasets. The complex refractive index within the window region of the spectrum $\left(8-12 \mu \mathrm{m}\right.$, or $\left.1200-800 \mathrm{~cm}^{-1}\right)$, i.e. where most thermal energy is contained and where the presence of dust will tend to act like a greenhouse gas, is of particular interest. Figure 2(c,d) show the real and imaginary parts for all four refractive index datasets used below in a sensitivity study, plotted against wave number. Note the peak in the imaginary part is within the window region and hence it has a crucial role in determining modelled radiances and irradiances. The imaginary part for the WMO dataset is notably much lower than the other schemes.

\section{Scattering phase functions}

Johnson and Osborne (2011) have shown that the asymmetry parameter (i.e. the cosine-weighted average of the phase function), important in simulations of radiative forcing, is significantly different for irregularshaped particles (i.e. complex particles having sharp edges) than for spheres and spheroids. The reasons for this difference are analysed further in this article in relation to the full phase function by using measured radiances over a range of forward scattering angles and comparing these to modelled data.

Aerosol size distribution data were not available during flight B295 due to poor instrument performance. Therefore the mean GERBILS size distribution (covering the particle radii between about 0.08 and $25 \mu \mathrm{m}$ ) from flights B299-B303, shown in Johnson and Osborne (2011), is used to generate phase functions for spheres, spheroids and irregular-shaped particles at specific wavelengths. Although an attempt has been made to correct in situ sizing methods for non-spherical particles at super-micron sizes (Johnson and Osborne, 2011), significant error potentially exists in the coarse mode data. A sensitivity study for the coarse mode aerosol is applied below for scattered radiance modelling through dust. For non-spherical shapes, equivalent area particle sizes have been assumed. The sphere and spheroid data have been generated using the Dubovik et al. (2006) spheroid software package. This package is based on a combination of T-matrix and modified geometric ray-tracing methods, where the latter is used for large size parameters (ratio of particle circumference to wavelength $>30-40)$. For our largest particle sizes and shortest wavelength, the size parameter reached about 150 . The spheroids were assumed to be randomly orientated 

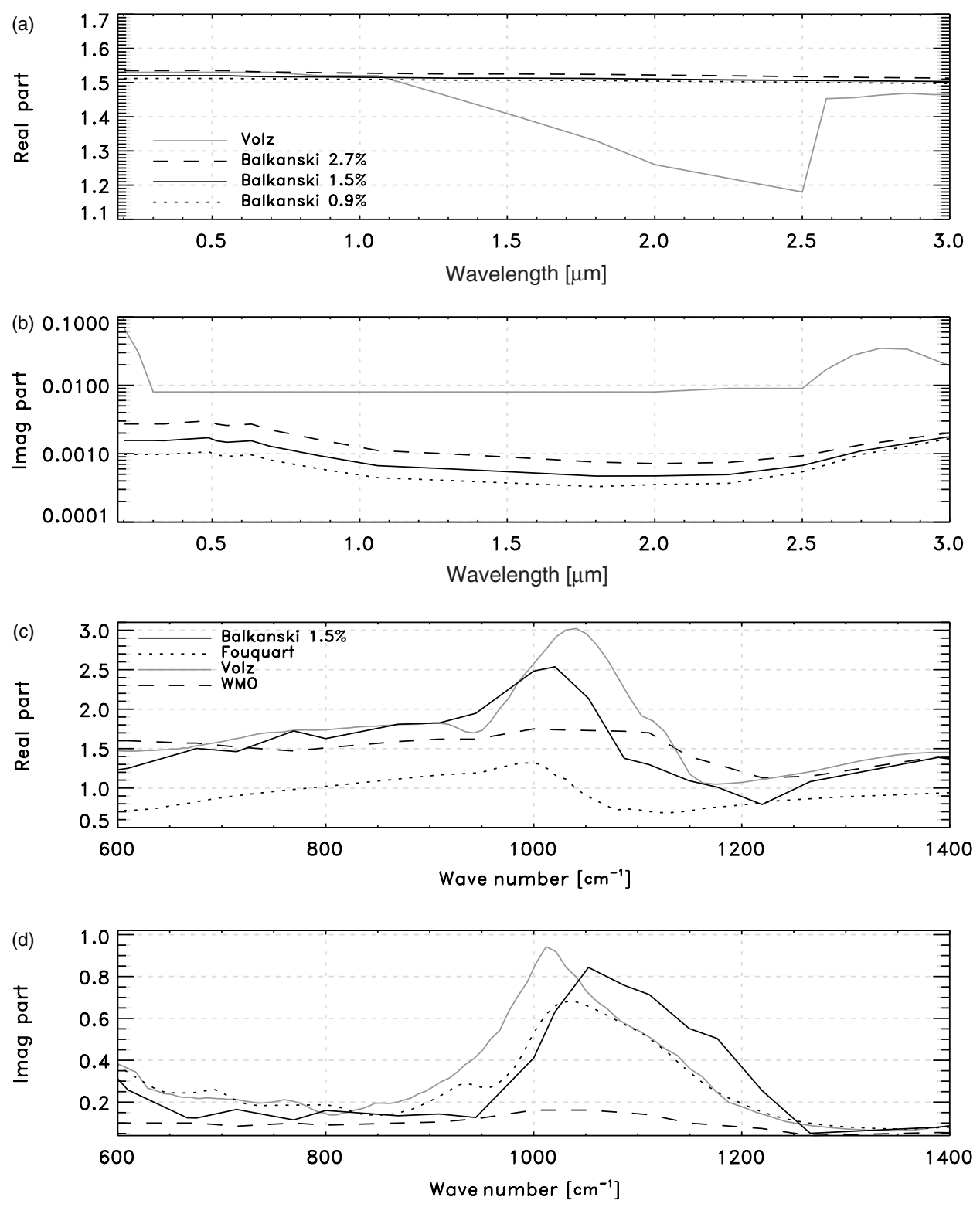

Figure 2. Real and imaginary parts of the dust index of refraction over the (a, b) short-wave and (c, d) long-wave spectra. (a) and (b) are plotted against wavelength and show the Volz (1973) data and the three hematite contents from Balkanski et al. (2007). (c) and (d) are in terms of wave number and show the 1.5\% hematite content of Balkanski et al. (2007), Fouquart et al. (1987), Volz (1973) and WMO (WCP, 1986).

prolate and oblate spheroids having a non-equal distribution of aspect ratios between 0.3 and 3.0 (skewed to larger aspect ratios) as described in Dubovik et al. (2006).

The shape distribution of the irregular-shaped particle model was assumed to consist of a mixture of hexagonal prisms of aspect ratio unity (the aspect ratio is defined as the column length to diameter) between 0.12 and $1 \mu \mathrm{m}$ radius and polyhedral particles between 1 and $20.0 \mu \mathrm{m}$ radius, with the aspect ratio of the polyhedral particles remaining invariant with respect to size. The polyhedral model, based on Macke et al. (1996), represents particle irregularity by randomising a second-generation triadic Koch fractal, commonly referred to as the 'polycrystal'. Although, the polycrystal model was originally applied to study the scattering properties of cirrus, it has also been applied to study the scattering properties of large mineral dust aerosols by Kokhanovsky (2003). In the paper by Kokhanovsky (2003) it was shown that the polycrystal could replicate to high accuracy laboratory-derived scattering phase matrices of mineral dust aerosol for a variety of complex refractive indices. In this article the single-scattering properties of the hexagonal prisms are computed using the T-matrix method of Havemann and Baran (2001) for radii less than $1 \mu \mathrm{m}$, and for radii greater than $1.0 \mu \mathrm{m}$ the method of ray-tracing diffraction on facets according to Hesse (2008) is applied to the randomised polycrystal. The polycrystal has been randomised using the method of distortion described by Macke et al. (1996). At each reflection and refraction event, the normal to the surface of the crystal is randomly tilted, $\theta_{\mathrm{t}}$, with respect to its original direction, with the degree of distortion defined as $\theta_{\mathrm{t}} / 90$. In this article we assume a distortion parameter of 0.4 as this level of distortion was shown to reasonably represent satellite measurements of the reflection and polarization properties of cirrus (Baran and Labonnote, 2006). Here we assume that the same level of disortion can be applied to mineral dust aerosols in order to represent their light-scattering properties. However, there is no evidence to support this assumption since the polycrystal has never been applied to airborne radiometric measurements of mineral dust before. 
(a)

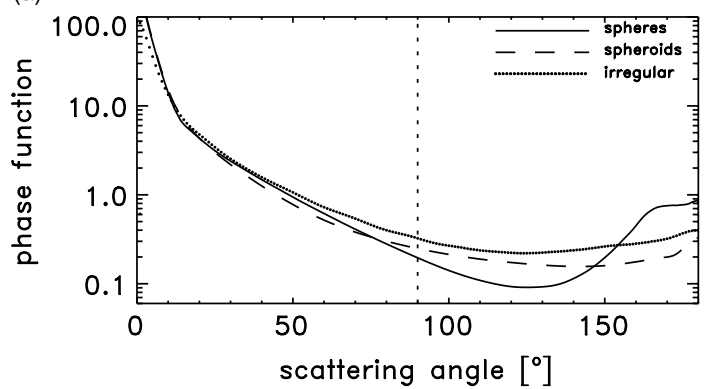

(b)

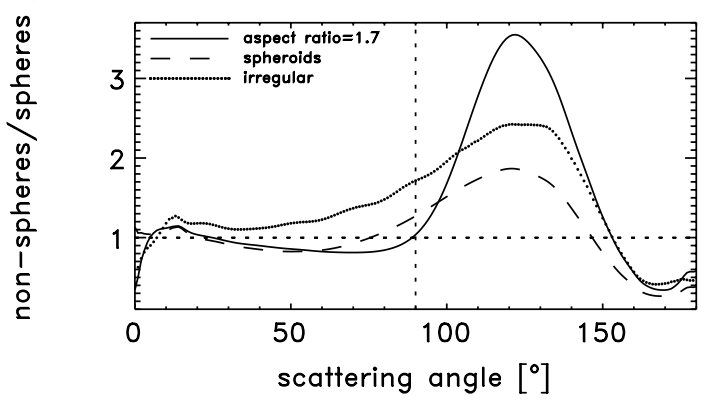

Figure 3. (a) Scattering phase functions at $0.55 \mu \mathrm{m}$ generated for dust particles of various shapes: spheres, spheroids having a distribution of aspect ratios, and irregular particles as described in the text. (b) Ratio of the non-spherical phase function to that for spheres for spheroids having a fixed aspect ratio of 1.7, spheroids having a distribution of aspect ratios, and irregular particles. The phase functions represent the integral over the aerosol size distribution function. The phase function $P(\Theta)$ is defined such that it satisfies the normalisation $\frac{1}{2} \int_{0}^{\pi} \mathrm{d} \Theta \sin \Theta P(\Theta)=1$, where $\Theta$ is the scattering angle.

Example phase functions integrated over the GERBILS size distribution at a wavelength of $0.55 \mu \mathrm{m}$ are shown in Figure $3(\mathrm{a})$. Side scattering $\left(20-80^{\circ}\right)$ relative to spheres has been increased for irregular-shaped particles and decreased for a mixture of spheroids. Figure 3(b) highlights this better by plotting the ratio of the spheroid and irregular phase functions to that for spheres. Also included in this figure is the result for spheroids having a fixed aspect ratio of 1.7 for all particle sizes. The difference in the back-scattering between assuming one fixed aspect ratio and a distribution of aspect ratios is large. The large differences in backscattering do not concern us here as the measurements did not encompass this region, but this is an area for future study. Note also the decrease in the forward scatter peak $\left(<15^{\circ}\right)$ for irregular-shaped particles.

\section{B295 case-study: short-wave sky radiances}

Aircraft orbits have been used previously to analyse the scattering properties of ice crystals within cirrus cloud (Foot, 1988; Francis et al., 1999a), industrial aerosol plumes (Francis et al., 1999b) and biomass-burning aerosol layers (Haywood et al., 2003b). Distributions of sky radiances as a function of scattering angle contain a strong signature of the aerosol phase function. Measurements of such distributions do not measure the phase function directly as there are also the effects of Rayleigh scatter, surface reflectance and, most importantly, multiple scattering between aerosol particles. Good agreement has been obtained between measured and modelled radiance distributions transmitted through aerosol layers where the assumption of spherical particles is realistic (e.g. Osborne et al., 2004, for biomass-burning aerosols). The

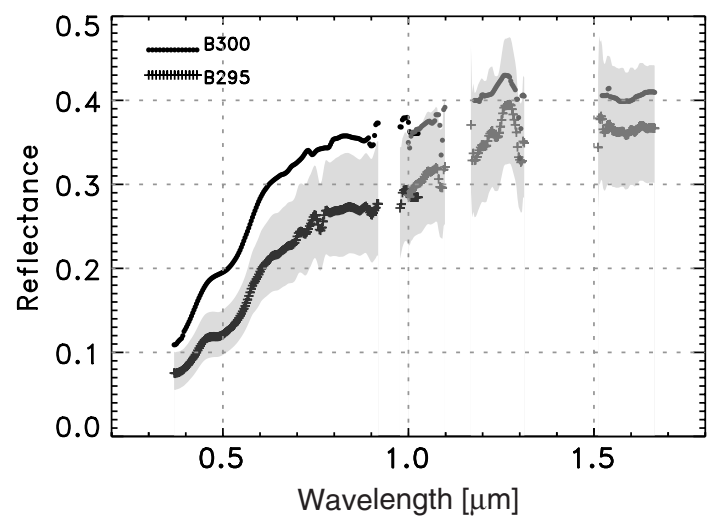

Figure 4. Measured spectral surface reflectance using upper and lower SHIMS from low-level runs during flights B295 (R4.1) and B300 (R2). The black symbols are from the short-wave module and the dark grey symbols are from the near-infrared module. The shaded area represents \pm 1 standard deviation of the B295 data.

object of the present work is to model radiance as a function of scattering angle using spherical and non-spherical particle scattering methods, and to compare the model results to the observations.

The Edwards-Slingo (ES) radiative transfer code (Edwards and Slingo, 1996), an offline version of the radiation code used in the Met Office Unified Model, has been used to model the downwelling scattered sky radiances at the altitude of the orbits (about $300 \mathrm{~m}$ above the ground). The radiances are resolved angularly in the ES code by decomposing the radiances into high-order spherical harmonics. A 220 band short-wave version of the code has been used previously to successfully model sky radiances transmitted through turbid atmospheres (Haywood et al., 2003b; Osborne et al., 2004). The model atmosphere (i.e. temperature, humidity, ozone) was based on a nearby aircraft profile. The reflectance of the desert surface has been determined using upper and lower SHIMS data from a lowlevel run just prior to the orbits. Figure 4 shows reflectance as a function of wavelength across the full SHIMS spectrum for B295, reflectance being the ratio of lower to upper SHIMS irradiance. The spectral dependence is in broad agreement with measurements over a desert basin surface (Morocco) shown by Bierwirth et al. (2009), i.e. with a strong gradient in the albedo between 0.5 and $0.6 \mu \mathrm{m}$. This measured spectral albedo is included in the model set-up. The model surface is assumed to be Lambertian as a more sophisticated treatment was not available for the ES code.

A series of four orbits, centred at position $15.19^{\circ} \mathrm{N}$, $0.01^{\circ} \mathrm{E}$, were performed below a heavy dust layer in cloudfree skies during flight B295 (19 June 2007). The aircraft was banked at $50^{\circ}$ during the orbits and each orbit took about $70 \mathrm{~s}$ to complete with the SWS sampling at $2 \mathrm{~Hz}$. The nephelometer profile indicates an AOD of $1.1 \pm 0.1$ (at a wavelength of $0.55 \mu \mathrm{m}$ ) in the vicinity of the orbits which includes a measure of absorption $(S S A=0.97)$. Figure 5(a) shows measured sky radiances versus scattering angle (i.e. off-sun almucantar scans) at four wavelengths (0.55, 0.62, $0.87,1.04 \mu \mathrm{m})$. The data have been averaged over all four orbits and binned into $2^{\circ}$ intervals. Modelled almucantars based on irregular-shaped particle scattering are also shown in Figure 5. These modelled lines represent our best attempt at describing the observations. The modelled AOD is 1.0 which is that AOD which provides the best overall fit. This value of AOD falls within the error range of the 

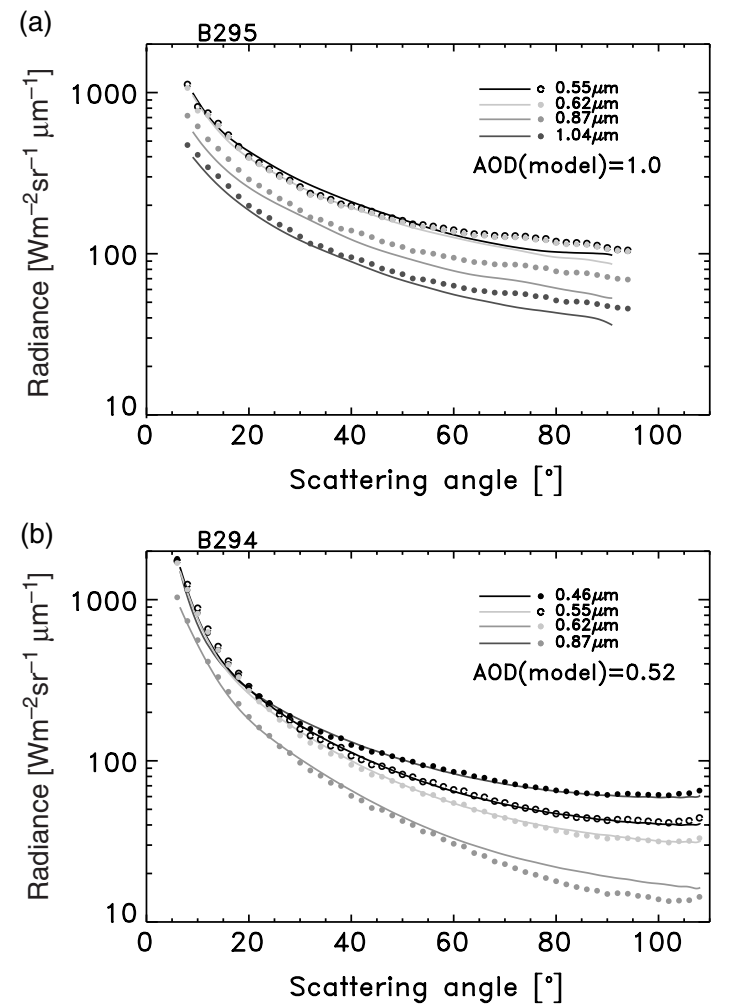

Figure 5. Scattered downwelling sky radiances as a function of scattering angle below the mineral dust layer during flights (a) B295 and (b) B294. Symbols are the short-wave spectrometer observations, lines are modelled data assuming irregular-shaped particles for B295 and spheroids for B294 (see text). Note that the choice of wavelengths differs in the two panels.

nephelometer AOD. Johnson and Osborne (2011) provide a description of the errors involved in the nephelometer data. The almost coincident observed data at 0.55 and $0.62 \mu \mathrm{m}$ are not captured by the modelling, possibly due to an error in the assumed refractive index, but the overall shape of the modelled lines is encouraging. Shorter wavelength radiances such as at $0.46 \mu \mathrm{m}$ lie very close to the 0.55 and $0.62 \mu \mathrm{m}$ curves, so they are not shown for clarity reasons. The similar scattering patterns across much of the visible spectrum explains the white appearence of the dust to the eye.

Figure 5(b) shows equivalent orbit data from flight B294 over the sea off the coast of Mauritania $\left(20.30^{\circ} \mathrm{N}, 17.75^{\circ} \mathrm{W}\right)$. The orbits took place at an altitude of $200 \mathrm{~m}$. Haywood et al. (2011b) provide more information on this flight. Interestingly, the model results shown in Figure 5(b) for spheroids provide an excellent solution for this case-study where the modelled AOD to achieve this agreement was 0.52 . Note the different wavelength choices for this case where we show $0.46 \mu \mathrm{m}$ instead of $1.04 \mu \mathrm{m}$. Although a larger range of scattering angles was captured during B294, the shape of the scattering patterns is different from B295: tighter convergence of the lines at shallow angles, and more spread between the lines at shorter wavelengths. The slight bulge in side scattering for the SWS data in B295 at around $80^{\circ}$ is not apparent in the B294 case. Back-trajectory analysis shows that the dust in flights B294 and B295 were clearly from different source regions and so it is possible that the particle shape and roughness were different. We do not have in situ size distributions from either of these days and so we have been forced to use the GERBILS campaign mean data in both cases. Therefore, in trying to obtain closure based on particle shape, we could be compensating for unknown errors in the sub-micron size distribution. Also, the AOD during $\mathrm{B} 295(\mathrm{AOD}=1.0)$ was double that during $\mathrm{B} 294(\mathrm{AOD}=0.52)$. It is noteworthy that in both case-studies a non-spherical solution provided the best results.

Figure 6 shows more details of the B295 orbit almucantars where each wavelength is displayed in a separate plot. In each case, the modelling has been carried out based on spheres, a mixture of spheroids and irregular-shaped particles. The modelled error in the scattering pattern caused by the error in the surface reflectance is shown in the grey shaded region for irregular particles. The modelled error caused by an assumed error in the dust refractive index (i.e. between the Balkanski refractive index 0.9 and $1.5 \%$ hematite contents) is shown in the black shaded region for spheres. Both of these error assessments are small compared to the difference in the modelled scattering between spheres and irregular-shaped particles. The increased side scattering for the irregularshaped particles improves the agreement over spheres and mixture of spheroids. The reduction in the forward scatter peak for irregular-shaped particles also improves matters for the shortest two wavelengths. A spheroid mixture decreases the side scattering relative to spheres and are therefore worse than spheres in this case-study (unlike the B294 case described above). The level of agreement for the irregular particles is not consistent with wavelength, which probably indicates an error in the spectral refractive index. The level of side scattering needs to be increased even further to gain agreement here, but the modelling attempt shows that the polycrystal model for irregular-shaped particles offers an improved solution to the problem compared to smooth spheres or spheroids.

The sensitivity of the almucantar plots to the aerosol size distribution has been tested by using an alternative to the GERBILS mean data. The fourth mode from the mean SAMUM size distribution from Weinzierl et al. (2009) is used instead of the GERBILS fourth mode to generate an alternative phase function based on irregular particles at $0.55 \mu \mathrm{m}$. The SAMUM size distribution is noted for its very large coarse mode at a radius of $10 \mu \mathrm{m}$ compared to the GERBILS data at $2 \mu \mathrm{m}$ (as shown in Johnson and Osborne, 2011). Relative to the GERBILS simulation above the 'SAMUM' simulation (not shown here) hugely increases the forward scattering peak (angles less than $10^{\circ}$ ) with a decrease in side-scattered energy, partly due to increased absorption. Due to much of the energy now within the forward peak, the AOD required to match the magnitude of the radiances for much of the range of interest is far too great to be realistic. Hence a coarse mode approaching the size of the SAMUM data is unrealistic for this case-study. It is clear that error in the assumed size distribution cannot explain the issue of side scattering. Sensitivity to the size distribution is revisited below with respect to long-wave radiation.

\section{B300 case-study: short-wave and long-wave radiative closure}

Flight B300 contained a Z-pattern manoeuvre, centred at $18.0^{\circ} \mathrm{N}, 6.45^{\circ} \mathrm{W}$, consisting of a $15 \mathrm{~min}(100 \mathrm{~km})$ lowlevel SLR ( $\mathrm{R} 2$ at $\approx 380 \mathrm{~m}$ above the ground) to measure downwelling radiances and surface reflectance below the dust, a profile (P3) ascent through the dust layer keeping within the footprint of the low-level SLR, and a high-level SLR (R3 at $7.5 \mathrm{~km}$ altitude) above the dust to measure upwelling radiances along the same track as the low-level 

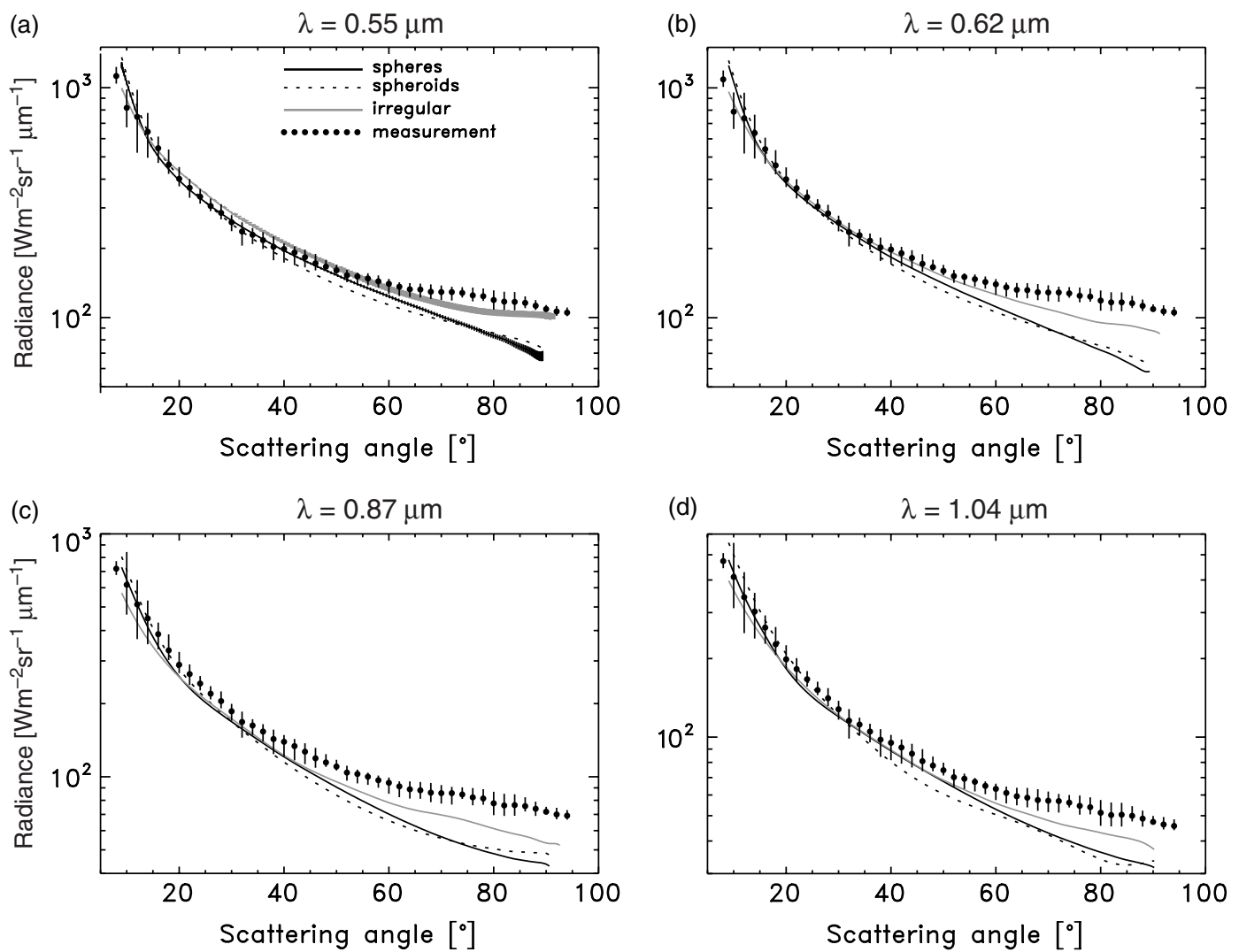

Figure 6. The observed sky radiances for the four wavelengths shown in Figure 5 compared to modelled data assuming spheres, a mixture of spheroids and irregular dust particles. For the $0.55 \mu \mathrm{m}$ case only, the grey shading shows the response in modelled radiance to the error in the surface reflectance, and the black shading shows an estimated error in refractive index (see text).

SLR. This pattern allowed us to determine the localised effect of dust on both short-wave and long-wave radiation within an approximate $1 \mathrm{~h}$ period. The procedure took place around local noon (which occurred mid-way through P3) and the surface temperature was rising through the measurement period from a measured $325 \mathrm{~K}$ during $\mathrm{R} 2$ to a predicted $332 \mathrm{~K}$ during $\mathrm{R} 3$. The surface temperature is crucial for modelling upwelling radiances within the window region of the spectrum. Profile descent P2 took place before the Z-pattern, was offset from it, and is used below to illustrate horizontal variability in the aerosol properties. The measured spectral surface reflectance during B300 is shown in Figure 4 and displays similar features to the B295 data but at a higher mean albedo at all wavelengths. The surface beneath the aircraft during the Z-pattern was completely devoid of vegetation with colours yellow, white and red predominating to the eye, but with some scattered blackish boulders.

Figure 7 shows the vertical structure of water vapour, ozone, air temperature and aerosol mass mixing ratio from profile P3. The water vapour specific humidity was derived from dew point measurements from a General Eastern 1011B chilled-mirror hygrometer. Temperature and humidity data are also included from a sonde dropped at high level during R3. For the aerosol profile the nephelometer scattering coefficients are plotted that are used to calculate short-wave AOD. The AOD (at $0.55 \mu \mathrm{m}$ ) derived from the nephelometer was 0.79 from P3, compared to 0.66 from P2. Given the error in the correction to the nephelometer (Johnson and Osborne, 2011) and other instrumental considerations, a measurement error of $\pm 20 \%$ in AOD is reasonable and means that the P3 AOD (0.79) has an error range of
0.66-0.95. Also included in Figure 7(a) is the GERBILS campaign mean nephelometer scattering profile at $0.55 \mu \mathrm{m}$ calculated from all available profile data over land; Johnson and Osborne (2011) provide a summary of the GERBILS flights.

\subsection{Short-wave spectral irradiance}

The asymmetry parameter of the mean GERBILS dust phase function (at $0.55 \mu \mathrm{m}$ ) was determined as 0.73 for spheres, 0.73 for a mixture of spheroids and 0.62 for irregular-shaped particles (Johnson and Osborne, 2011). The difference between irregular-shaped particles and spheres/spheroids therefore becomes potentially important in terms of the effect on short-wave irradiances at the TOA and at the surface.

Upper and lower SHIMS measurements of spectral irradiance have been used to assess the effect of the mineral dust layer on the short-wave upwelling and downwelling spectral irradiances. A two-stream version of the ES code has been used to model this effect by simulating pristine-sky and aerosol-laden sky irradiances. The SHIMS spectral albedo measured during R2 (Figure 4) was used in the simulations. Of note is a distinct gradient in the surface reflectance along the run which amounted to a change of $20 \%$ at $0.55 \mu \mathrm{m}$. Figure 8 shows four ways of viewing the resultant comparison of model and observed spectra. Each spectrum, whether measured or modelled, represents a $15 \mathrm{~min}$ run average. All modelled spectra shown in Figure 8 represent spherical dust particles. Haywood et al. (2011b) show that the effect of particle type (spheres, spheroids, or irregular) on the irradiance spectral shape is fairly small, based on 
(a)

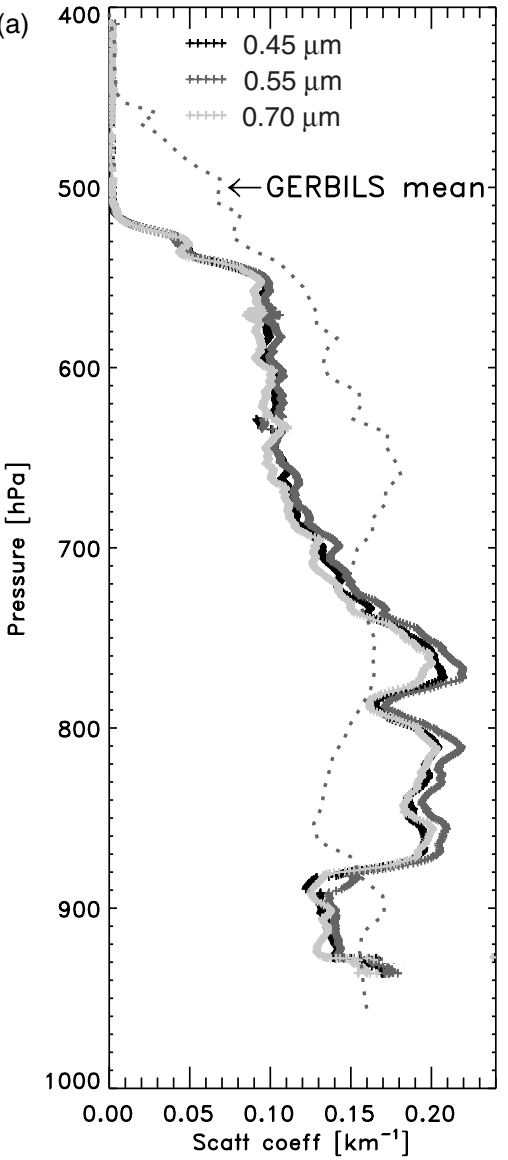

(b)
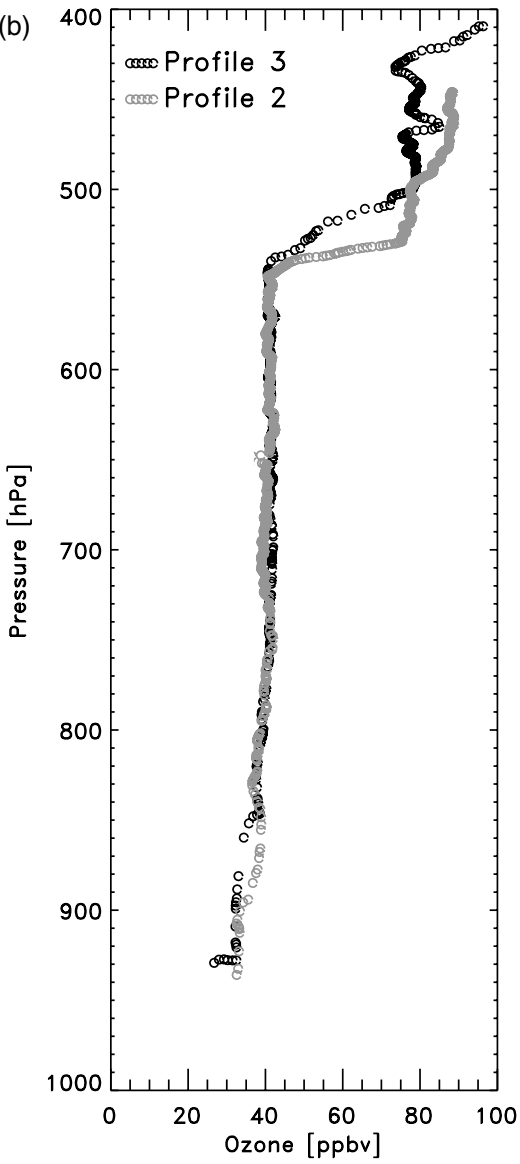

(c)

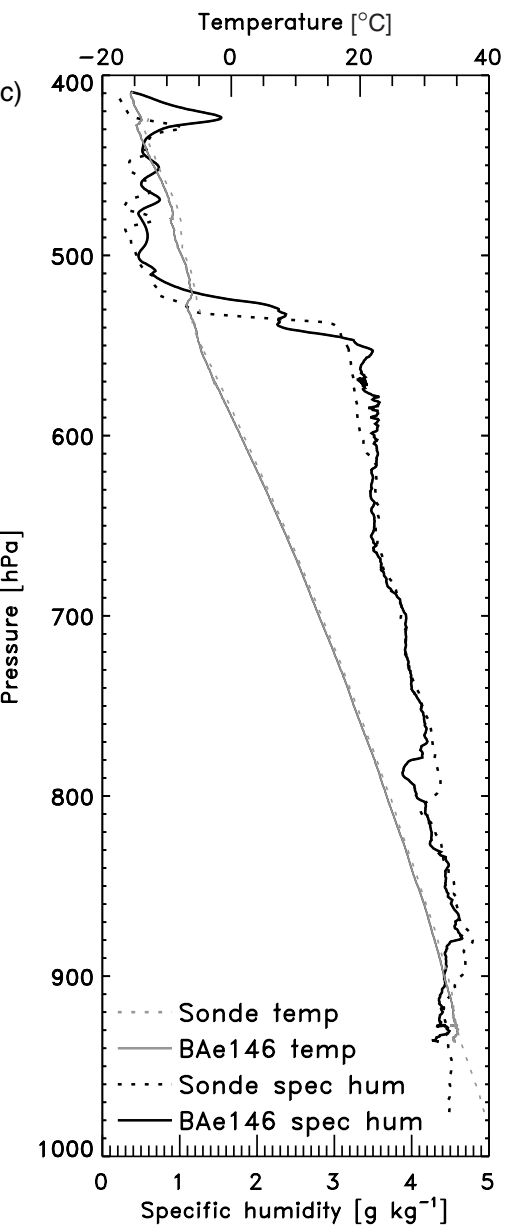

Figure 7. Vertical structure of the B300 atmosphere between the surface and $400 \mathrm{hPa}$ (a) nephelometer total scattering coefficients at three visible wavelengths from profile 3 , also including the GERBILS mean $0.55 \mu \mathrm{m}$ scattering profile, (b) ozone mixing ratio from profiles 2 and 3 , and (c) comparison of aircraft (profile 3 ) and dropsonde water vapour specific humidities and air temperatures.

two-stream modelling like the spectra in Figure 8. However, the effect of particle morphology on the instantaneous DRE can be important because of its influence on the asymmetry parameter, and is included in Table I. Its effect on the diurnal DRE is demonstrated in section 7.

The instantaneous, spectrally resolved, low-level DRE is shown in Figure 8(a), where DRE is defined as the modelled pristine-sky irradiance minus the irradiance with aerosol (whether measured or modelled) for downwelling radiation during the low-level run (R2). The dust has an effect at all wavelengths across the SHIMS spectrum up to $1.7 \mu \mathrm{m}$. Integrations of these two spectra show the instantaneous short-wave aerosol DRE at low-level is $-168 \pm 27 \mathrm{~W} \mathrm{~m}^{-2}$ (based on SHIMS where the error is 3\% of the downwelling total irradiance). This value is put into context in Table I where all surface and TOA DREs are summarized for SHIMS and all three modelled particle shapes (across the wavelength range 0.3-1.7 $\mu \mathrm{m}$ ). Figure 8(b) shows observed and simulated downwelling spectra at high and low level i.e. the low-level SHIMS data here are the same as shown in (a). The low-level model data provide the best match for the peak in the spectrum at $0.55 \mu \mathrm{m}$, and imply a modelled AOD of 0.92 (for spheroids) which is within measurement uncertainty (20\%) for the nephelometer AOD from profile P3. The AOD implied using irregular-shaped particles to match the SHIMS data was 1.0, a little higher than the range of uncertainty in the in situ AOD. The high-level data are in excellent agreement because this is downwelling irradiance
Table I. Instantaneous direct radiative effect $\left(\mathrm{W} \mathrm{m}^{-2}\right)$ across the wavelength range $0.3-1.7 \mu \mathrm{m}$ at the 'surface' (R2) and 'top-of-atmosphere' (R3) during the Z-pattern of flight B300. Values are derived from SHIMS measurements and modelling based on the assumption of dust spheres, a mixture of spheroids, and irregular-shaped particles.

\begin{tabular}{lrrcc}
\hline & SHIMS & Spheres & Spheroids & Irregulars \\
\hline R2 'surface' & -168 & -143 & -135 & -130 \\
R3 'TOA' & 70 & 59 & 61 & 15 \\
\hline
\end{tabular}

in pristine skies such as was used for the calibration of SHIMS during flight B294 over the sea. Of more concern is the lowlevel comparison where some discrepancies are apparent, especially for wavelengths greater than $0.7 \mu \mathrm{m}$ where the modelled spectrum is greater than the measurements. This could be due to errors in the assumptions of size distribution and refractive index, as surmised by Haywood et al. (2011b). As seen in Table I, all the modelled surface DREs produce smaller negative values than the SHIMS DREs; this can be explained by the differences in the spectral shapes.

DRE can likewise be defined at high level as the outgoing irradiance as modelled in pristine conditions minus the irradiance with aerosol (either measured or modelled). Figure 8(c) shows these data, again with an aerosol signature 
(a)

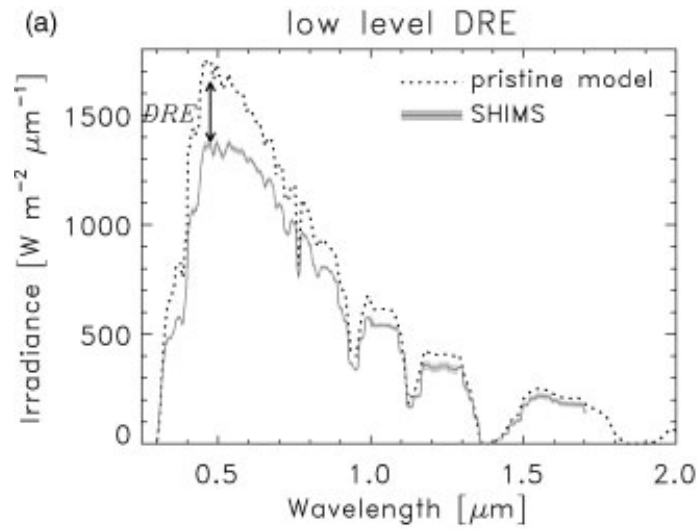

(c)

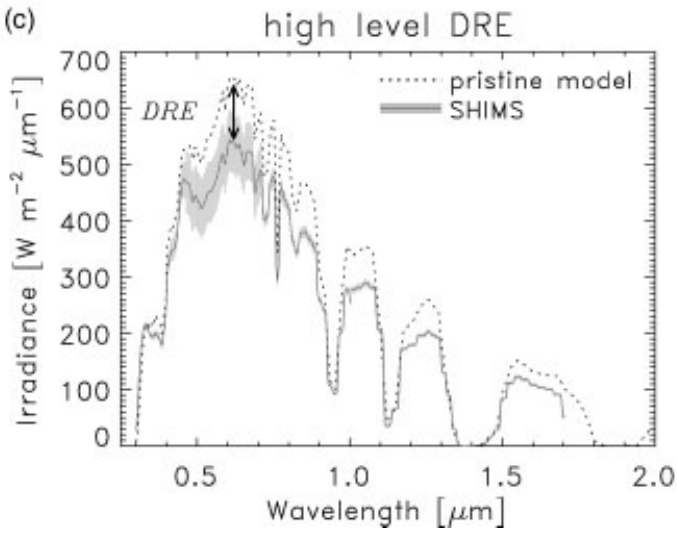

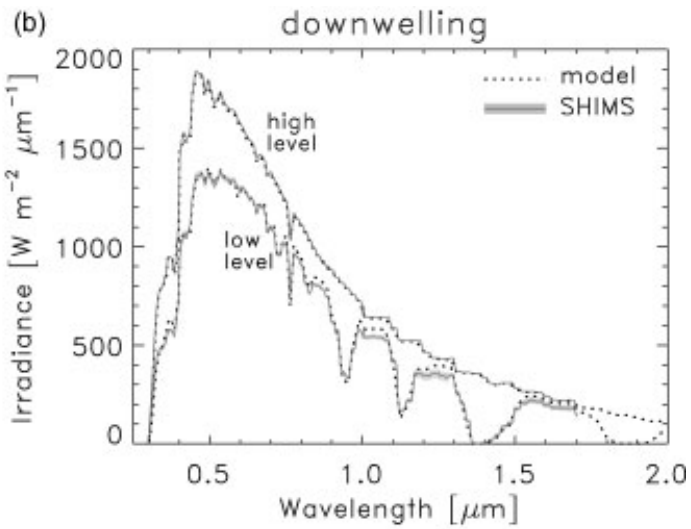

(d)

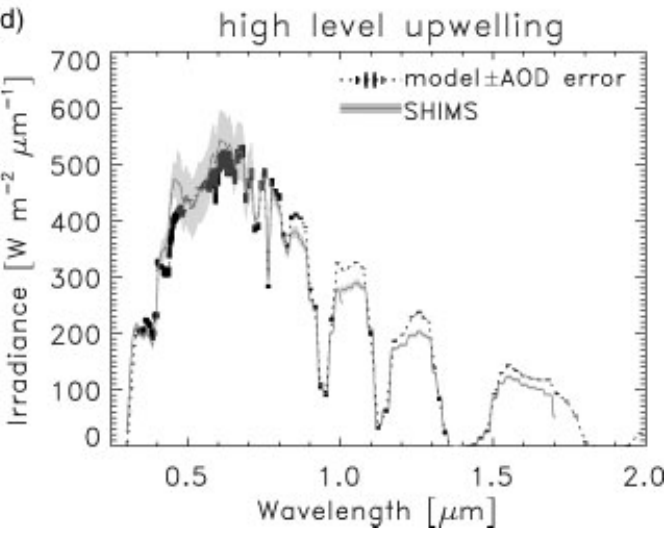

Figure 8. Comparison of SHIMS and modelled short-wave irradiance spectra based on run mean conditions: (a) R2 low level showing downwelling SHIMS data and modelled spectrum without aerosol (turn single quotation mark around. 'pristine model') to demonstrate the spectral DRE; (b) downwelling spectra at high (R3) and low (R2) level; (c) upwelling SHIMS irradiances at high level (R3) with the modelled spectrum without aerosol to demonstrate the DRE; and (d) upwelling spectra at high level, where the model error represents the \pm 0.15 error in AOD. The SHIMS grey shading represents \pm 1 standard deviation.

at all wavelengths. Integration of the spectra shows that the instantaneous DRE at high level is $70 \pm 13 \mathrm{~W} \mathrm{~m}^{-} 2$ (based on SHIMS). Table I indicates that the assumption of spheres or a mixture of spheroids produces the best agreement with SHIMS and that irregular particles produce a much lower high-level DRE $\left(15 \mathrm{~W} \mathrm{~m}^{-2}\right)$ assuming a fixed AOD. The estimate of the short-wave instantaneous DRE with positive values between 15 and $70 \mathrm{~W} \mathrm{~m}^{-2}$ (close to local noon) is consistent with past studies of dust forcing over a desert surface (e.g. Quijano et al., 2000).

The variability in the upwelling irradiance along this run is much larger than the downwelling irradiance at low level and is explained by the change in the surface reflectance mentioned above. Figure $8(\mathrm{~d})$ is our best attempt to model the SHIMS spectrum at high level by including aerosol in the model in the AOD range 0.66-0.95. The variability suggested by the error in the aerosol column is smaller than the variability in the SHIMS data i.e. caused by changes in the surface albedo. As with the downwelling spectra in Figure $8(\mathrm{~b})$, the model indicates higher irradiances than SHIMS for wavelengths greater than about $0.8 \mu \mathrm{m}$. There are also differences at smaller wavelengths that were not apparent in the downwelling comparison. These are probably due to errors in the aerosol optical properties assumed in the model, such as the spectral refractive index.

An error in DRE for spheres has been calculated based on the difference in refractive index using the Balkanski refractive index 0.9 and $1.5 \%$ hematite contents. Appropriate for comparison with Table I, the error in surface (R2 level) DRE for an AOD of 0.79 is $24 \mathrm{~W} \mathrm{~m}^{-2}$. The associated error

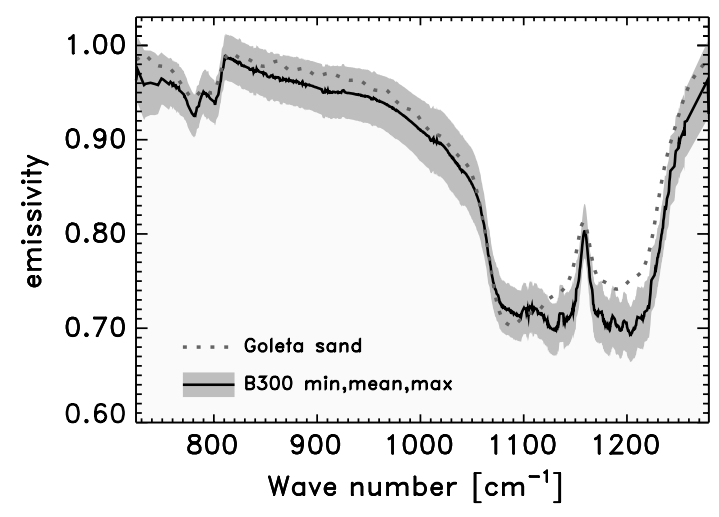

Figure 9. Flight B300 emissivity spectrum across the window region as derived from ARIES nadir and zenith radiances measured at low level. The black line is the mean spectrum and the grey region shows the full variability. Also included for comparison is the spectrum for Goleta sand.

in 'TOA' (R3 level) DRE is $21 \mathrm{~W} \mathrm{~m}^{-2}$. These values represent the modelled change in short-wave absorption by the dust. Although significant, the 'TOA' DRE error $\left(21 \mathrm{~W} \mathrm{~m}^{-2}\right)$ is about half the modelled DRE difference between spheres and irregular particles at 'TOA' $\left(44 \mathrm{~W} \mathrm{~m}^{-2}\right)$.

\subsection{Long-wave radiative effects}

We now present the effect of mineral dust on longwave radiances within the window region $(8-12 \mu \mathrm{m}$ or $1200-800 \mathrm{~cm}^{-1}$ ) for the $\mathrm{B} 300$ case study using a combination 


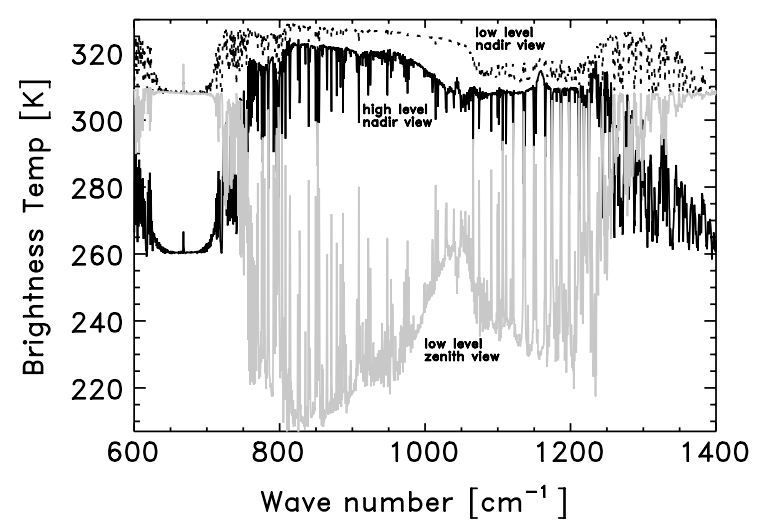

Figure 10. Full resolution ARIES brightness temperature as a function of wave number during flight B300 from high-level nadir view (black), low-level nadir view (dotted) and low-level zenith view (grey).

of aircraft observations and ES modelling. Case-studies have previously been analysed over the sea where pristinesky and aerosol-laden measurements were possible either within one flight (Haywood et al., 2011b) or across two flights (Highwood et al., 2003), thereby allowing a direct measure of the direct long-wave effect due to aerosol. For the GERBILS data over land this has not been possible due to no dust-free conditions being found and strong geographical variations in surface spectral albedo.

The presence of the dust lowers the surface temperature relative to non-aerosol conditions due to reflection of incoming solar radiation. Therefore the TOA reduction in OLR is caused by a combination of this short-wave effect and the absorption of thermal outgoing radiation and its re-emission at a lower temperature. Haywood et al. (2005) show that the short-wave effect contributes at most 25-35\% to the total reduction in OLR and is therefore considered a second-order effect.

\subsubsection{Initialising the model}

A 300 band $\left(10 \mathrm{~cm}^{-1}\right.$ wave number resolution) long-wave version of the ES code was used in a similar manner to Highwood et al. (2003). A two-stream version of the code is used to generate the long-wave fluxes in section 7.2, but a full radiance version using spherical harmonics is used to simulate the ARIES spectra. The aerosol scattering data in the model, like the short-wave version, is based on the measured mean GERBILS size distribution (Johnson and Osborne, 2011) and the Balkanski complex refractive index. The sensitivity to refractive index and size distribution is explored below, but it is noted here that the difference between the GERBILS mean size distribution and that measured during the $\mathrm{Z}$-pattern of flight $\mathrm{B} 300$ produced very small changes in the modelled long-wave spectra compared to errors in other parameters. Non-spherical effects are expected to be small for long-wave calculations (Haywood et al., 2005) and so Mie-Lorenz theory has been used to generate the scattering properties of the particles.

The aerosol loading is biased to relatively low altitudes, as can be seen in Figure 7(a). The vertical position (i.e. temperature) of the dust is very important in determining the brightness temperature when viewed from above. Highwood et al. (2003) showed that a $100 \mathrm{hPa}$ shift in the dust layer can change the brightness temperature by $\approx 3 \mathrm{~K}$. The vertical positioning of the main plume features in Figure $7(\mathrm{a})$ between profiles $\mathrm{P} 3$ and $\mathrm{P} 2$ varied by only $\approx 10 \mathrm{hPa}$, so we consider the height error to be negligible. The ozone data are shown from profiles 2 and 3 to demonstrate a fairly well-mixed layer within the dust and also little variability between the two profiles. Strong reduction of ozone is noted within the dust layer relative to the free troposphere above and a gradient of the ozone mixing ratio towards the surface. The aircraft temperature and specific humidity profiles are compared to a dropsonde that was deployed at the top of profile 3 and show good agreement. Differences between the aircraft and sonde profiles have a negligible effect on the modelled long-wave properties.

The thermal radiation emitted from the desert surface depends on the surface skin temperature and the surface emissivity. Nadir and zenith radiances during R2 at low level allow us to retrieve the ARIES surface temperature and infrared emissivity using the method of Newman et al. (2005). This retrieved temperature is based on a multi-spectral technique and was used in preference to the Heimann KT 19.82 broadband (8-14 $\mu \mathrm{m})$ aircraft radiometer data. The ARIES temperatures were typically 4-5 K greater than the Heimann temperatures due to the Heimann derivation assuming a fixed high surface emissivity and also due to absorption by ozone and carbon dioxide in the atmosphere between the aircraft and the desert surface. Use of the Heimann skin temperatures produced modelled brightness temperatures that were unrealistically low.

Figure 9 shows the mean emissivity spectrum of the desert surface based on ARIES data, its variability and a comparison to measurements taken of Goleta (California) sand taken from the Moderate Resolution Imaging Spectrometer (MODIS) UCSB emissivity library at the University of California, Santa Barbara (http://www.icess.ucsb.edu/modis/EMIS/html/em.html). These surface data were used to initialise the ES code assuming a Lambertian reflection scheme. As assessment of the likely errors involved using a Lambertian scheme was not possible. The surface temperature increase along R2 was noted and extrapolated in time to provide us with a surface temperature mid-way along $\mathrm{R} 3(\approx 332 \mathrm{~K})$, so that the upwelling radiance could be modelled at that altitude.

\subsubsection{ARIES brightness temperatures}

The ARIES radiances have been converted into brightness temperatures for the analysis that follows. Figure 10 shows full-resolution ARIES brightness temperatures from R2 (zenith and nadir below the majority of the dust) and R3 (nadir above the dust) covering the range $600-1400 \mathrm{~cm}^{-1}$, i.e. this includes the $\mathrm{CO}_{2}$ absorption band $\left(670 \mathrm{~cm}^{-1}\right)$ and the water vapour continuum and methane lines above $1250 \mathrm{~cm}^{-1}$. Both nadir views show a signature of the surface emissivity but at high-level (R3) the ozone band $\left(1040 \mathrm{~cm}^{-1}\right)$ also affects the shape of the spectrum. The difference between the R2 and R3 nadir spectra (between 800 and $1200 \mathrm{~cm}^{-1}$ ) is mainly due to dust aerosol that has absorbed and re-emitted terrestrial radiation at a lower temperature.

Here we concentrate on the nadir view as this is the view seen by satellite instruments, although similar modelling techniques can be used to explore the aerosol effect in the window region using zenith views from low and high level. Much of the broad hump in the low-level zenith ARIES spectrum in Figure 10 between 800 and $1200 \mathrm{~cm}^{-1}$ is due to aerosol, albeit with a strong ozone peak. Although for 


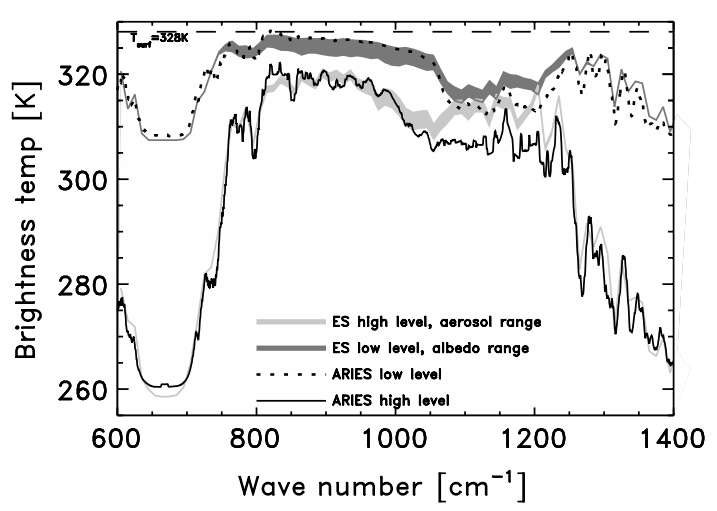

Figure 11. Comparison of measured and modelled nadir views of brightness temperature across the window region. ARIES data have been degraded to the same resolution of the ES model. For the high-level modelling runs, the light grey shading represents the range due to AOD between profiles 2 and 3. For the low-level runs, the dark grey shading represents the error in surface albedo. The $328 \mathrm{~K}$ line represents the surface temperature retrieved during the low-level run.

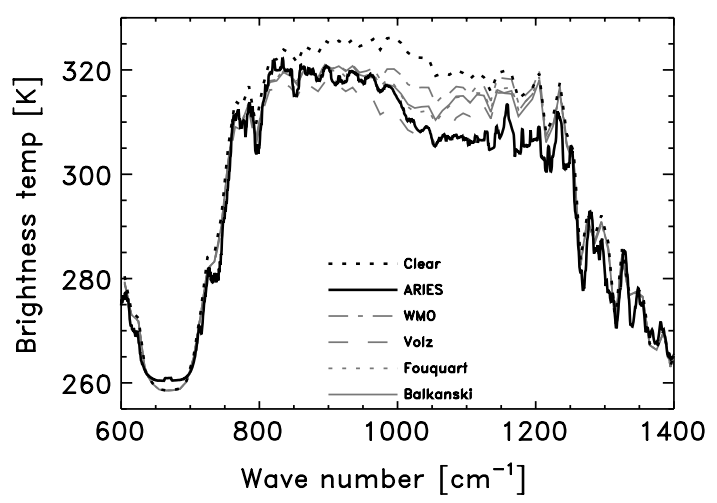

Figure 12. Comparison of ARIES-measured nadir brightness temperatures at high level to equivalent model runs based on pristine sky and various aerosol refractive indices as described in the text.

zenith views we do not have the concern of the surface spectral albedo, the simulated spectra are more sensitive to the vertical profiles. The ES code has been used to simulate the nadir brightness temperatures and test their sensitivity to the surface albedo and the aerosol properties of column mass loading, refractive index and size distribution. Figure 11 shows the ARIES nadir data from Figure 10, but degraded in resolution to be approximately equal to the ES code resolution. The low-level model data show the range of values expected from the measured range in the surface albedo. The surface temperature was set to $328 \mathrm{~K}$ (that derived from ARIES data). Agreement is good apart from the $1050-1250 \mathrm{~cm}^{-1}$ region where the brightness temperatures are too high. The could be due to an error in the retrieved spectral emissivity or poorly represented properties for the aerosol in the bottom few hundred metres of the atmosphere below the level of the aircraft. The highlevel model data show the range of values expected, given the range in measured AOD (0.66-0.79). For this model run the surface spectral albedo was set to its minimum value (this gave the best results) and the surface temperature was set to $332 \mathrm{~K}$. Again, the agreement is impressive apart from the $1050-1250 \mathrm{~cm}^{-1}$ region, which seems to be an exacerbation of the error at low level. Error in the aerosol refractive index in this spectral region is possibly the largest source of error here.
The sensitivity of nadir brightness temperatures to the aerosol refractive index is explored in Figures 12 and 13. The effect of the Balkanski refractive index is compared to that of the Volz, Fouquart, WMO datasets relative to the ARIES measurements. The short-wave AOD is set to 0.79 (profile P3) for all cases, i.e. a fixed aerosol mass profile. The pristine-sky modelled data are shown in Figure 12 and are used to calculate the 'pristine minus aerosol' brightness temperature differences in Figure 13(a), and the 'ARIES-model' differences in Figure 13(b). All the modelled brightness temperatures in the $800-1000 \mathrm{~cm}^{-1}$ region perform in a reasonable manner with the exception of the WMO scheme. However, between 1000 and $1200 \mathrm{~cm}^{-1}$ none of the refractive index datasets can account for the measurements. This is clear from the $5 \mathrm{~K}$ differences between the ARIES and Balkanksi model data at about $1100 \mathrm{~cm}^{-1}$ in Figure 13(b). Differences in the brightness temperature spectra can be reconciled by viewing differences in the imaginary part of the refractive index across the window region as shown in Figure 2. The minimum brightness temperature difference $\left(-13\right.$ to $-14 \mathrm{~K}$ at just over $\left.1000 \mathrm{~cm}^{-1}\right)$ of the Balkanski refractive index spectrum is in agreement with the 'pristine minus ARIES' spectrum as shown in Figure 3(a). The Volz version also performs adequately, less so the Fouquart, and worst of all the WMO dataset. It may seem that the strong minimum in Figure 13 is coincident with the ozone absorption band, but this plot shows a temperature difference where the ozone profile is identical for the model runs with and without aerosol. Therefore the spectral shape in Figure 13 is a direct signature of the effect of mineral dust. The effect of ozone, incidentally, occurs between 1000 and $1070 \mathrm{~cm}^{-1}$ and reduces the nadir brightness temperatures in this case by $1.5-2.5 \mathrm{~K}$.

Brightness temperature differences are shown in Figure 13(c) which compares 'pristine minus ARIES' with differences for various aerosol size distributions (all using the Balkanski refractive index): the mean GERBILS data, the mean GERBILS data with the coarse mode reduced in magnitude by a factor of two, and the coarse mode SAMUM data described in Weinzierl et al. (2009) as mentioned above for the short-wave calculations. The aerosol mass profile was varied so that the short-wave AOD was set to 0.79 in each case. The greatest sensitivity is in the $750-950 \mathrm{~cm}^{-1}$ region with very little sensitivity at wave numbers greater than $1000 \mathrm{~cm}^{-1}$ (i.e. less than $10 \mu \mathrm{m}$ wavelength). We conclude that a SAMUM-type of size distribution for the coarse mode aerosol produces poor results for the modelled brightness temperatures and that the sensitivity of the modelled spectra to the imaginary part of the refractive index, which after all cannot be readily determined, is greater than the sensitivity to a realistic error in the GERBILS size distribution.

\section{B300 diurnal radiative forcing}

\subsection{Short-wave}

The DRE is defined in this section as the difference between the modelled pristine-sky irradiance and the modelled irradiance with aerosol, either at the surface or TOA (i.e. not the height of the runs as used in section 6.1). The sign of the DRE is designated such that a positive value implies a net addition of energy to the atmosphere. The two-stream version of the ES code is used for all the irradiance modelling. We show in Figure 14(a) the variation in the short-wave (i.e. 

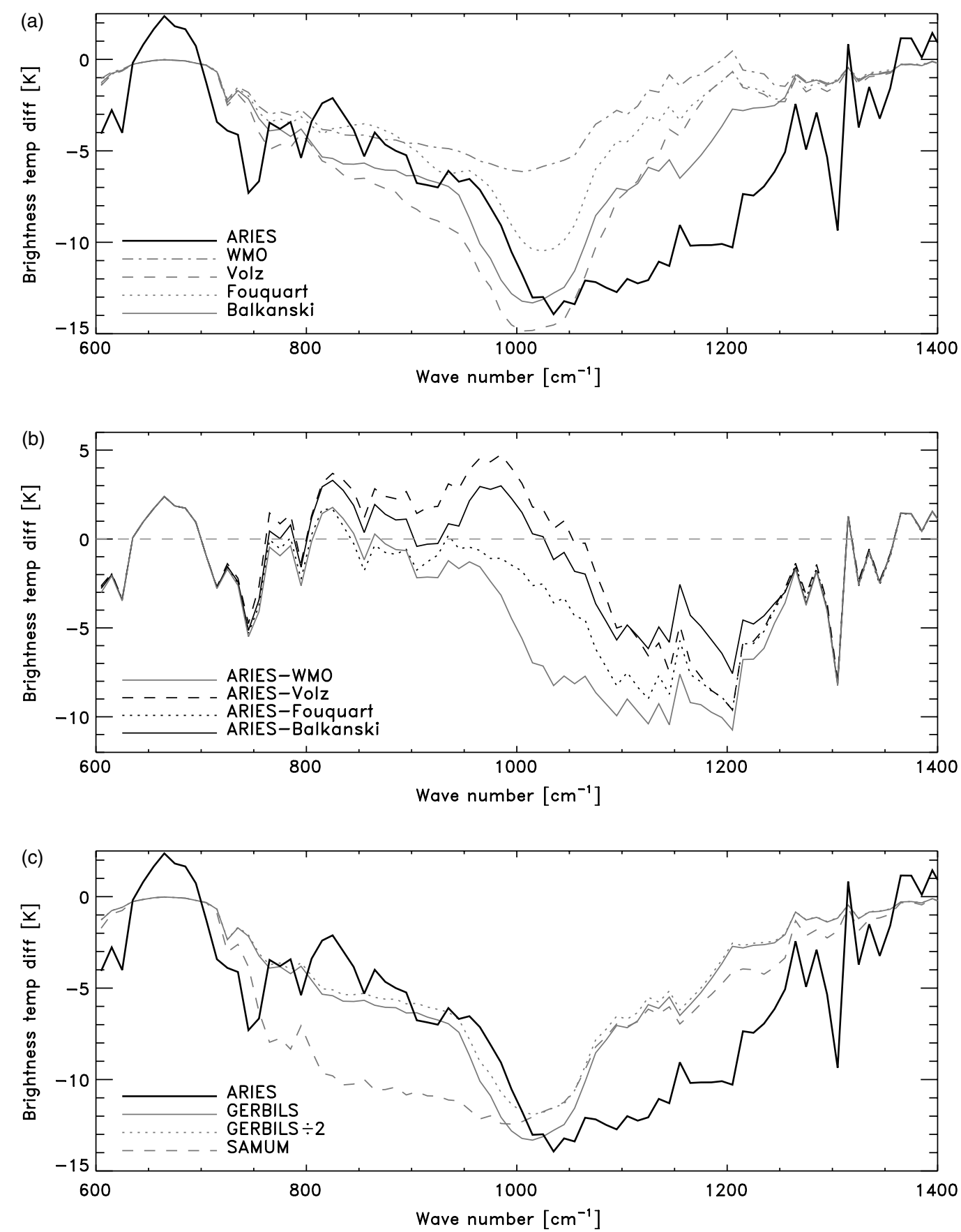

Figure 13. B300 case-study high-level nadir brightness temperature differences: (a) pristine sky minus ARIES, and pristine sky minus various aerosol model runs based on different refractive indices; (b) ARIES data minus various aerosol models based on different refractive indices; (c) pristine sky minus ARIES, and pristine sky minus various aerosol model runs based on different aerosol size distributions: GERBILS data, GERBILS data with the coarse mode magnitude reduced by a factor of 2, and the mean SAMUM data taken from Weinzierl et al. (2009). The aerosol mass mixing ratio is constant for all cases and indicates an AOD at $0.55 \mu \mathrm{m}$ of 0.79 .

here set to $0.3-3 \mu \mathrm{m})$ dust DRE (DRE $\mathrm{DW}_{\mathrm{sw}}$ ) as a function of time (local time is equal to UTC) during the daylight hours of case B300. The minimum solar zenith angle on the day of flight B300 was about $8^{\circ}$.

The model has been run assuming spheres, a mixture of spheroids and irregular-shaped particles where the AOD was kept constant at 0.79 . Both show minima a few hours after sunrise and a few hours before sunset. Although the $\mathrm{DRE}_{\mathrm{sw}}$ increases with increasing solar zenith angle, the decreasing solar irradiance at long slant paths means that peak magnitude $\mathrm{DRE}_{\mathrm{SW}}$ is achieved at intermediate solar zenith angles. This effect is apparent for downwelling radiation at the surface and upwelling radiation at TOA.
The surface $\mathrm{DRE}_{\mathrm{sw}}$ is negative throughout the day for all particle shapes and is caused by a strong overall reflection of radiation back to space. The greatest difference in the surface $\mathrm{DRE}_{\mathrm{sw}}$ between spheres and non-spheres occurs during the middle of the day. The daily mean $\mathrm{DRE}_{\mathrm{sw}}$ at the surface and TOA are summarized in Table II, where the mean was calculated from one-hourly model runs throughout the day; also included here are the radiative forcing efficiencies i.e. the $\mathrm{DRE}_{\mathrm{sw}}$ per unit AOD. The $\mathrm{DRE}_{\mathrm{sw}}$ is approximately, but not precisely, proportional to the AOD. The error in the surface $D_{R E}$ (for spheres), based on the error in the aerosol column, is $\pm 19 \mathrm{~W} \mathrm{~m}^{-2}$. This implies that differences in the DRE between the three particle shapes are relatively 
small. The error in the diurnal mean surface DRE implied by the refractive index difference between the Balkanski refractive index for 0.9 and $1.5 \%$ hematite contents has been calculated for spheres as $\pm 17 \mathrm{~W} \mathrm{~m}^{-2}$ per unit AOD. This is similar to the difference in surface DREs modelled with spheres and irregular particles for unit AOD (Table II).

The TOA DRE $E_{s w}$ is negative at low sun angles and goes positive for a length of time that varies with particle shape: spheres and spheroids behave similarly with a daily mean very close to zero, and irregular-shaped particles show a daily mean $\mathrm{DRE}_{\mathrm{sw}}$ of $-20 \mathrm{~W} \mathrm{~m}^{-2}$. This difference results from the lower asymmetry parameter for irregular-shaped particles. Even at an AOD of unity, the daily mean $\mathrm{DRE}_{\mathrm{sw}}$ at TOA is still close to zero for spheres and a mixture of spheroids. The refractive index error (as described previously) at TOA is $\pm 15 \mathrm{~W} \mathrm{~m}^{-2}$ per unit AOD, again a significant potential source of error.

The instantaneous $\mathrm{DRE}_{\mathrm{sw}}$ is dependent on the aerosol optical properties (AOD, single scatter albedo, asymmetry parameter), surface albedo, and the solar zenith angle. The positive $\mathrm{DRE}_{\mathrm{sw}}$ at TOA at low solar zenith angles would be of greater magnitude, for example, if the dust aerosol had been more absorbing (i.e. single scatter albedo less than 0.97 ), or the surface had been more reflective. Given a daily mean $\mathrm{DRE}_{\mathrm{sw}}$ at TOA of close to zero, it so happens that the small amount of aerosol short-wave absorption and the measured surface albedo imply that the $\mathrm{DRE}_{\mathrm{sw}}$ at TOA is at the threshold between cooling and warming. When comparing these values to others in the literature, the difference in assumed dust SSA should be borne in mind as this probably explains why the diurnal mean values here are close to zero or negative.

\subsection{Long-wave}

Here we model the perturbation to the outgoing long-wave radiation using the $\mathrm{ES}$ code for the $\mathrm{B} 300$ case-study. The outgoing irradiances as a function of wave number have been modelled for a range of conditions, i.e. pristine skies, aerosol based on profiles 2 and 3, changes in albedo, and changes in surface temperature. Figure 15 shows modelled upwelling irradiance spectra at TOA for pristine-sky and aerosol cases from profiles 2 and 3 based on a surface radiating at $332 \mathrm{~K}$ (based on $\mathrm{R} 3$ conditions close to local noon). The major energy perturbation between pristine and aerosol-laden skies is between 800 and $1200 \mathrm{~cm}^{-1}$, although there are other small differences outside this region. The difference in these integrated spectra suggest the dust decreases the peak outgoing long-wave irradiance, $D_{R E}$, by $23.9 \pm 3.5 \mathrm{~W} \mathrm{~m}^{-2}$ based on profile $3(\mathrm{AOD}=0.79)$ and the Balkanski refractive index. This error of $3.5 \mathrm{~W} \mathrm{~m}^{-2}$ is comparable to the modelled change in outgoing irradiance $\left(3.3 \mathrm{~W} \mathrm{~m}^{-2}\right)$ caused by the maximum error in the surface albedo. A $5 \mathrm{~K}$ change in the surface temperature implies a change of $8.2 \mathrm{~W} \mathrm{~m}^{-2}$ in the long-wave flux, although the accuracy of our surface temperature measurement using ARIES is much better than this.

$\mathrm{DRE}_{\mathrm{lw}}$ at TOA has been modelled over a $24 \mathrm{~h}$ period based on the B300 conditions. For each test run using a different aerosol refractive index, all parameters were held constant except the surface temperature which was allowed to cycle based on the ECMWF skin temperature 6-hourly analyses averaged over the GERBILS campaign period for the model grid point containing the $\mathrm{B} 300 \mathrm{Z}$-pattern. The diurnal range
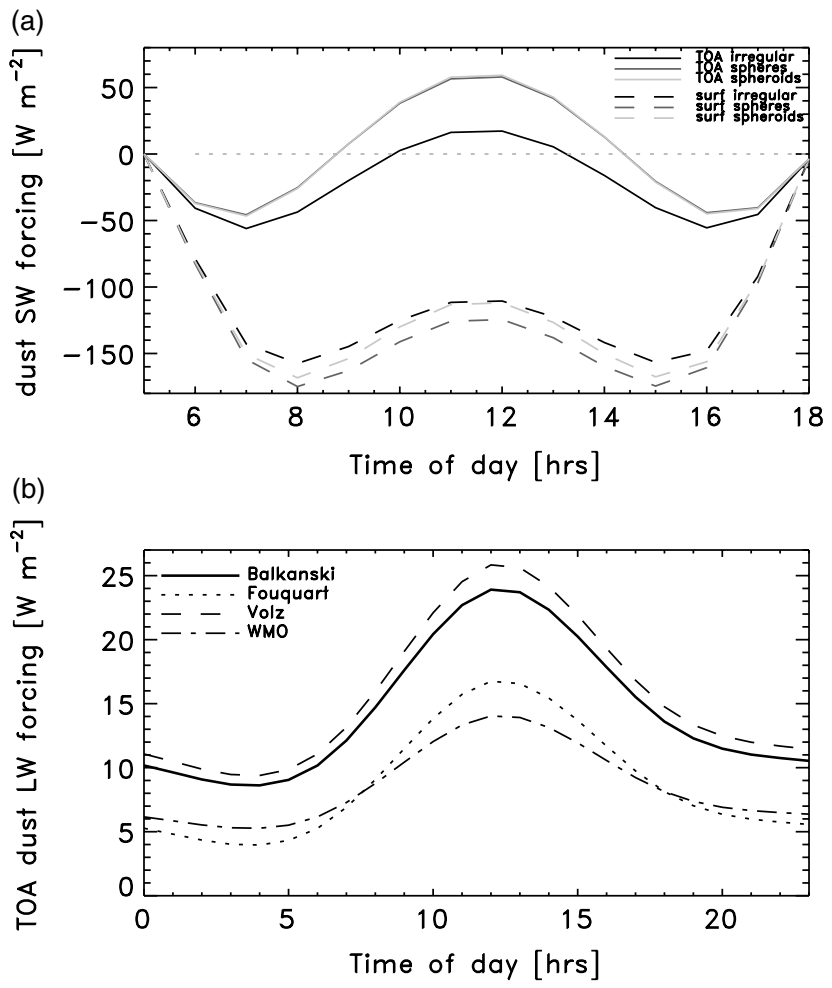

Figure 14. (a) Modelled short-wave $(0.3-3 \mu \mathrm{m})$ aerosol direct radiative effect at the surface and TOA across all daylight hours at $1 \mathrm{~h}$ resolution based on the B300 Z-pattern profiles (e.g. AOD=0.79). (b) Modelled long-wave aerosol direct radiative effect at TOA over a $24 \mathrm{~h}$ period at $1 \mathrm{~h}$ resolution based on the B300 profiles (e.g. same aerosol mass column as for short-wave).

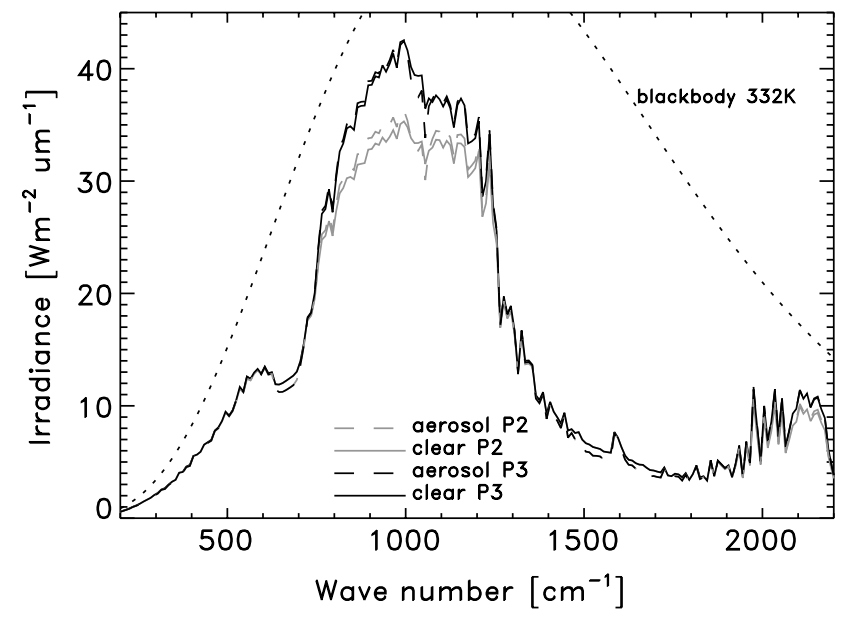

Figure 15. Modelled upwelling (nadir view) irradiances at TOA during pristine and aerosol conditions for flight B300. Runs are included based on profiles 2 and 3 to represent probable error in the aerosol column. The theoretical black-body emission curve from a surface at $332 \mathrm{~K}$ is also included.

and peak skin temperatures from the ECMWF data were fairly stable over the campaign period with no discernable trend. The peak ECMWF temperature was then increased by about $5 \mathrm{~K}$ to equal the skin temperature $(332 \mathrm{~K})$ at midday, which implies a diurnal range in skin temperature of $304-332 \mathrm{~K}$. A spline fit was made to the data so that 1-hourly model points could be generated.

Figure 14(b) shows the modelled TOA DRE $\mathrm{lw}_{\mathrm{w}}$ (i.e. difference in upwelling irradiance between pristine-sky and aerosol-sky) based on the four datasets of refractive index. 
Table II. Simulated short-wave $(0.3-3 \mu \mathrm{m})$ direct radiative effect $\left(\mathrm{W} \mathrm{m}^{-2}\right)$ averaged over all daylight hours at the surface and top-of-atmosphere (TOA) based on the B300 case-study having an $\mathrm{AOD}=0.79$ and $\mathrm{AOD}=1.0$. The error in DRE due to the error in AOD is estimated to be $\pm 19 \mathrm{~W} \mathrm{~m}^{-2}$ (see text).

\begin{tabular}{lrrrrrrr}
\hline & \multicolumn{3}{c}{$\mathrm{AOD}=0.79$} & & \multicolumn{3}{c}{ AOD $=1.0$} \\
\cline { 2 - 3 } & Spheres & Spheroids & Irregulars & & Spheres & Spheroids & Irregulars \\
\hline Surface & -122 & 115 & 110 & & -153 & -146 & -137 \\
TOA & 0 & 0 & -20 & -2 & -2 & -25 \\
\hline
\end{tabular}

Table III. Simulated long-wave direct radiative effect $\left(\mathrm{W} \mathrm{m}^{-2}\right)$ averaged over a $24 \mathrm{~h}$ period at top-of-atmosphere (TOA) and the surface based on the B300 case-study having a short-wave $\mathrm{AOD}=0.79$ and $\mathrm{AOD}=1.0$. Values have been generated for the four refractive index datasets as described in the text. The error in the Balkanki DRE $\mathrm{lw}_{\mathrm{w}}$ due to the error in AOD is estimated to be $\pm 2.2 \mathrm{~W} \mathrm{~m}^{-2}$ at TOA, and $\pm 4.3 \mathrm{~W} \mathrm{~m}^{-2}$ at the surface (see text).

\begin{tabular}{lccccccccc}
\hline & \multicolumn{4}{c}{ AOD $=0.79$} & & \multicolumn{4}{c}{ AOD $=1.0$} \\
\cline { 2 - 3 } & Balkanski & Volz & Fouquart & WMO & & Balkanski & Volz & Fouquart & WMO \\
\hline Surface & 30.7 & 32.7 & 24.4 & 17.5 & & 36.3 & 38.6 & 29.2 & 21.3 \\
TOA & 14.4 & 15.5 & 8.5 & 8.4 & & 17.2 & 18.3 & 10.6 & 10.3 \\
\hline
\end{tabular}

In each case the AOD (at $0.55 \mu \mathrm{m}$ ) has been set to 0.79 . $\mathrm{DRE}_{\mathrm{lw}}$ is positive for all times and all refractive indices i.e. there is a net gain of energy to the atmosphere. The shape of the $\mathrm{DRE}_{\mathrm{l}}$ curves mimics that of the skin temperature with a cosine curve around midday and an exponential decay through the night with a minimum around dawn. The diurnal $(24 \mathrm{~h})$ mean $\mathrm{DRE}_{\mathrm{lw}}$ for both TOA and the surface for the flight B300 conditions are summarized in Table III. The peak midday $\mathrm{DRE}_{\mathrm{l}_{\mathrm{w}}}$ are 23.9 (Balkanski refractive index), 25.8 (Volz), 16.7 (Fouquart) and 14.0 (WMO) $\mathrm{W} \mathrm{m}^{-2}$. The error of the Balkanski refractive index diurnal mean TOA $\mathrm{DRE}_{\mathrm{lw}_{\mathrm{w}}}$ due to the aerosol profile amounts to $\pm 2.2 \mathrm{~W} \mathrm{~m}^{-2}$; therefore the Balkanski and Volz refractive index $\mathrm{DRE}_{\mathrm{lw}}$ are considered similar. The diurnal mean long-wave radiative forcing efficiencies (i.e. $\mathrm{DRE}_{\mathrm{lw}}$ per unit short-wave AOD) are included in Table III where the Balkanski refractive index aerosol scheme shows a mean value of $17.2 \mathrm{~W} \mathrm{~m}^{-2} \mathrm{AOD}^{-1}$.

To place these diurnal mean forcings for our casestudy in greater context, a mean diurnal forcing has been calculated based on the average aerosol, temperature, ozone and water vapour profiles from all the available aircraft ascents and descents over land during the campaign from eight flights (Johnson and Osborne, 2011). The mean nephelometer scattering profile is shown in Figure 7. Although the AOD from this profile (0.85) is similar to the B300 AOD (0.79), the difference in vertical structure, i.e. with more aerosol at higher level in the mean profile, means that the campaign-mean long-wave dust forcing is significantly greater at $18.5 \pm 7.9 \mathrm{~W} \mathrm{~m}^{-2}$ at $\mathrm{AOD}=0.85$, or about $20.5 \mathrm{~W} \mathrm{~m}^{-2} \mathrm{AOD}^{-1}$ (again based on Balkanski refractive index). The error range here is based on the rather large standard deviation $( \pm 0.44)$ from the campaign mean AOD. This has been a fairly quick and easy figure to derive since we have used the B300 surface emissivity and ECMWF skin temperature cycle based on one grid box of data. A more substantial study, outside the scope of this paper, is possible using available surface emissivity data from long $(\sim 2 \mathrm{~h})$ runs at low level along the $18^{\circ} \mathrm{N}$ line during flights B301 and B302.
The satellite analysis of Allan et al. (2011) finds the pertubation to the outgoing long-wave radiation, i.e. model minus GERB satellite data, of about $18 \mathrm{~W} \mathrm{~m}^{-2}$ for 25 June 2007. This has been averaged over the region bounded by $10^{\circ} \mathrm{W}-10^{\circ} \mathrm{E}, 20-25^{\circ} \mathrm{N}$ and over the times 0900, 1200 and 1500 UTC. The 0900-1500 UTC average from Figure 14(b) indicates a Balkanski refractive index $\mathrm{DRE}_{\mathrm{lw}}$ of $21.0 \pm 2.4 \mathrm{~W} \mathrm{~m}^{-2}$. Bearing in mind the geographical averaging of the Allan et al. data, i.e. we are not comparing like with like, this comparison is considered encouraging. A 0900-1500 UTC campaign (18-27 June 2007) mean DRE lw $_{\mathrm{l}}$ of $26.0 \mathrm{~W} \mathrm{~m}^{-2}$ based on aircraft data compares with a lower Allan et al. campaign mean value of about $20 \mathrm{~W} \mathrm{~m}^{-2}$-again, not discouraging considering the different natures of the two datasets.

\section{Conclusions}

Two case-studies have been described to demonstrate the effect of Saharan dust aerosol on some properties of shortwave and long-wave radiation. Both case-studies took place in cloud-free skies over a land surface. The B295 case-study concentrated on demonstrating measurements of the shortwave scattered sky radiances and attempts at modelling them using the ES code. The B300 case-study attempted a full radiative closure in terms of both the short-wave and long-wave spectrum.

For the short-wave radiances plotted as a function of scattering angle, the irregular-shaped particles with sharp edges were shown to provide an overall better modelled solution than either the spherical or spheroidal mixture assumptions. Although the large amount of side scattering was not fully captured at longer wavelengths, the results were quite good at $0.55 \mu \mathrm{m}$. Further iterations using some form of the polycrystal model might provide the side scattering required at longer wavelengths. This B295 case was constrasted with orbits from flight B294 over the sea where excellent agreement was found between the SWS radiances and those modelled with smooth spheroids at 
visible wavelengths. These different results are difficult to reconcile, but the AOD during B295 was about double that during B294 and the dust was probably sourced from different regions and so may have had different physical and optical properties. A future project on modelling the full range of scattering angles for dust aerosol (i.e. backscattering out to $180^{\circ}$ ) based on irregular particles is planned. This project will use aircraft orbit measurements above dust layers looking down with the SWS. Such future work should also look at a full short-wave spectral variation where the assumed spectral refractive index could explain some of the errors at longer wavelengths seen in the present work.

The first use of the SHIMS instrument on the BAe146 aircraft for measuring upwelling and downwelling spectral irradiances has been made. The short-wave surface reflectance spectrum was measured directly during low-level runs over the desert surface. This surface albedo was then used in two-stream modelling studies with the ES code. The spectral DRE was determined using SHIMS data and the equivalent modelled spectra without aerosol. The spectral shape did not vary significantly with the assumed particle shape (spheres, a mixture of spheroids or irregulars). The best agreement between the measured and modelled spectra indicate a modelled AOD of 0.92 for spheroids, which is within the $20 \%$ error of the nephelometer AOD of 0.79 . This fared better than the AOD implied from using irregularshaped particles $(A O D=1.0)$, but this probably shows the limitation using of two-stream modelling. The use of higherstream modelling for upwelling radiation was not attempted due to the assumed Lambertian surface (no other surface treatment was available for the ES code). Comparison of the measured and modelled irradiance spectra showed the largest discrepancies in the upwelling radiation, which can be explained given the range of variability in the surface reflectance as well as errors in the wavelength-dependent asymmetry parameter.

Given the measured AOD at $0.55 \mu \mathrm{m}$ of 0.79 , the aerosol mass mixing ratio that gives this AOD using the short-wave version of the ES code was used to model the long-wave brightness temperatures. These temperatures agreed reasonably well with the measured ARIES brightness temperatures. The dust layer during B300 showed peak nadir-viewing brightness temperature differences of $14 \mathrm{~K}$ within the window region of the spectrum. The sensitivity analysis of the effect of dust refractive index on the brightness temperature showed that the Balkanski refractive index dataset was adequate but on balance no better than the Fouquart or Volz schemes. The WMO refractive index, as concluded by other recent studies, performs the poorest. The point about the Balkanski refractive index scheme is that for short-wave properties it is the dataset that provides the best closure with the in situ measurements (Johnson and Osborne, 2011), and so across the complete short- and long-wave spectrum the Balkanski refractive index scheme fares the best.

The sensitivity of both the short-wave and long-wave properties to size distribution was investigated. For the longwave brightness temperature spectra, use of the SAMUM data produced a poorer simulation than the use of the GERBILS data, i.e. there was too much absorption and hence too much reduction in brightness temperature within the window region. For the short-wave almucantar radiances, the SAMUM coarse mode data significantly altered the phase function such that side scattering was massively reduced and hence highly unrealistic AODs were implied. Although it is expected that a large error exists in our coarse mode aerosol measurements which will affect the scattered sky radiances, it is clear that a more complete solution to the problem lies in increasing the amount of ray distortion in the scattering scheme and hence side scattering at angles greater than $60^{\circ}$. Whilst it is feasible that the huge differences in the aerosol size distributions between GERBILS and SAMUM can be partially explained through instrumental errors and artefacts, it seems likely that the differences are largely real and due to variations in dust plume strength, age and source region.

One of the chief aims of GERBILS was to assess the perturbation to the outgoing long-wave radiation due to airborne dust. Outgoing long-wave irradiances were modelled for a pristine and aerosol-laden atmosphere based on the aircraft data. The difference between the two shows a case-study perturbation of $14.4 \mathrm{~W} \mathrm{~m}^{-2}$ averaged over a $24 \mathrm{~h}$ period. The outgoing long-wave perturbation implied from satellite and model data in Allan et al. (2011) for the 0900-1500 UTC time period suggests a value of $18 \mathrm{~W} \mathrm{~m}^{-2}$. The equivalent 0900-1500 UTC value from the aircraft data is $21.0 \pm 2.4 \mathrm{~W} \mathrm{~m}^{-2}$, which is encouraging. The mean diurnal short-wave effect at TOA suggests a range between zero (for spheres and spheroids) and $-20 \mathrm{~W} \mathrm{~m}^{-2}$ (for irregular-shaped particles). The associated error in the TOA short-wave DRE due to an assumed refractive index error (of $40 \%$ in the imaginary part) was estimated to be $15 \mathrm{~W} \mathrm{~m}^{-2}$, which is significant when considering the net short-wave and longwave radiative balance at TOA. The outgoing long-wave and short-wave effects at TOA are likely to cancel each other out to some degree, leaving for this case-study a near-zero DRE across the combined short-wave and long-wave regions.

Future studies across the long wave could perhaps benefit by use of a line-by-line radiation code instead of a band model, but this may depend on the application. For determining the sensitivity to aerosol refractive index and aerosol mass loading, and hence deriving a perturbation and likely error to the outgoing thermal irradiance, the ES band model has been suitable and relatively easy to manipulate in the present study. However, for future comparisons with an interferometer like ARIES, a line-by-line resolution code would be preferable.

\section{Acknowledgements}

FAAM is jointly funded by the Met Office and the Natural Environment Research Council. The authors would like to thank the staff at FAAM, DirectFlight Ltd and Avalon Aero Ltd during operations in GERBILS. Oleg Dubovik (University of Lille) is thanked for help with the use of the spheroid software package.

\section{References}

Allan RP, Woodage MJ, Milton SF, Brooks ME, Haywood JM. 2011. Examination of long-wave radiative bias in general circulation models over North Africa during May-July. Q. J. R. Meteorol. Soc. 137: 1179-1192, DOI: 10.1002/qj.717.

Balkanski Y, Schulz M, Claquin T, Guibert S. 2007. Reevaluation of mineral aerosol radiative forcings suggests a better agreement with satellite and AERONET data. Atmos. Chem. Phys. 7: 81-95.

Baran AJ, Labonnote LC. 2006. On the reflection and polarization properties of ice cloud. J. Quant. Spectrosc. Radiat. Transfer 100: 41-54. 
Bierwirth E, Wendisch M, Ehrlich A, Heese B, Tesche M, Althausen D, Schladitz A, Müller D, Otto S, Trautmann T, Dinter T, von HoyningenHuene W, Kahn R. 2009. Spectral surface albedo over Morocco and its impact on radiative forcing of Saharan dust. Tellus B 61: 252-269.

Brindley H. 2007. Estimating the top-of-atmosphere longwave radiative forcing due to Saharan dust from satellite observations over a west African surface site. Atmos. Sci. Lett. 8: 74-79.

de Reus M, Fischer H, Sander R, Gros V, Kormann R, Salisbury G, Van Dingenen R, Williams J, Zöllner M, Lelieveld J. 2005. Observations and model calculations of trace gas scavenging in a dense Saharan dust plume during MINATROC. Atmos. Chem. Phys. 5: 1787-1803.

Deepshikha S, Satheesh SK, Srinivasan J. 2006. Dust aerosols over India and adjacent continents retrieved using METEOSAT infrared radiance. Part II: Quantification of wind dependence and estimation of radiative forcing. Ann. Geophys. 24: 63-79.

Dubovik O, Holben B, Eck TF, Smirnov A, Kaufman YJ, King MD, Tanré D, Slutsker I. 2002. Variability of absorption and optical properties of key aerosol types observed in worldwide locations. J. Atmos. Sci. 59: 590-608.

Dubovik O, Sinyuk A, Lapyonok T, Holben BN, Mishchenko M, Yang P, Eck TF, Volten H, Muñoz O, Veihelmann B, van der Zande WJ, Leon JF, Sorokin M, Slutsker I. 2006. Application of spheroid models to account for aerosol particle nonsphericity in remote sensing of desert dust. J. Geophys. Res. 111: D11208, DOI: 10.1029/2005JD006619.

Edwards JM, Slingo A. 1996. Studies with a flexible new radiation code. Part I: Choosing a configuration for a large-scale model. Q. J. R. Meteorol. Soc. 122: 839-861.

Foot JS. 1988. Some observations of the optical properties of clouds. II: Cirrus. Q. J. R. Meteorol. Soc. 114: 145-164.

Formenti P, Rajot J-L, Desboeufs K, Caquineau S, Chevaillier S, Nava S, Gaudichet A, Journet E, Triquet S, Alfaro SC, Chiari M, Haywood JM, Coe H, Highwood EJ. 2008. Regional variability of the composition of mineral dust from western Africa: Results from the AMMA SOP0/DABEX and DODO experiments. J. Geophys. Res. 113: D00C13, DOI: 10.1029/2008JD009903.

Forster P, Ramaswamy V, Artaxo P, Berntsen T, Betts R, Fahey DW, Haywood JM, Lean J, Lowe DC, Myhre G, Nganga J, Prinn R, Raga G, Schulz M, Van Dorland R. 2007. Changes in atmospheric constituents and in radiative forcing. In Climate Change 2007: The Physical Science Basis. Contribution of Working Group 1 to the Fourth Assessment Report of the Intergovernmental Panel on Climate Change. Solomon S, Qin D, Manning M, Chen Z, Marquis M, Averyt K, Tignor MMB, Miller HL. (eds.) 130-234, Cambridge University Press: London and New York.

Fouquart Y, Bonnel B, Brogniez G, Buriez JC, Smith L, Morcrette JJ. 1987. Observations of Saharan aerosols: Results of ECLATS field experiment, Part II: Broadband radiative characteristics of aerosols and vertical flux divergence. J. Clim. Appl. Meteorol. 26: 38-52.

Francis PN, Foot JS, Baran AJ. 1999a. Aircraft measurements of the solar and infrared radiative properties of cirrus and their dependence on ice crystal shape. J. Geophys. Res. 104: 31685-31695.

Francis PN, Hignett P, Taylor JP. 1999b. Aircraft observations and modeling of sky radiance distributions from aerosol during TARFOX. J. Geophys. Res. 104: 2309-2319.

Havemann S, Baran AJ. 2001. Extension of T-matrix to scattering of electromagnetic plane waves by non-axisymmetric dielectric particles: application to hexagonal ice cylinders. J. Quant. Spectrosc. Radiat. Transfer 70: 139-158.

Haywood JM, Boucher O. 2000. Estimates of the direct and indirect radiative forcing due to tropospheric aerosols: A review. Rev. Geophys. 38: 513-543. DOI: 10.1029/1999RG000078.

Haywood JM, Francis PN, Osborne SR, Glew M, Loeb N, Highwood EJ, Tanré D, Myhre G, Formenti P, Hirst E. 2003a. Radiative properties and direct radiative effect of Saharan dust measured by the C-130 aircraft during SHADE. 1. Solar spectrum. J. Geophys. Res. 108(D18): 8577, DOI: 10.1029/2002JD002687.

Haywood JM, Francis PN, Dubovik O, Glew M, Holben B. 2003b. Comparison of aerosol size distributions, radiative properties, and optical depths determined by aircraft observations and Sun photometers during SAFARI 2000. J. Geophys. Res. 108: 8471, DOI: 10.1029/2002JD002250

Haywood JM, Allan RP, Culverwell I, Slingo A, Milton S, Edwards J, Clerbaux N. 2005. Can desert dust explain the outgoing long-wave radiation anomaly over the Sahara during July 2003? J. Geophys. Res. 110: D05105, DOI: 10.1029/2004JD005232.

Haywood JM, Pelon J, Formenti P, Bharmal N, Brooks M, Capes G, Chazette P, Chou C, Christopher S, Coe H, Cuesta J, Derimian Y, Desboeufs K, Greed G, Harrison M, Heese B, Highwood EJ, Johnson B, Mallet M, Marticorena B, Marsham J, Milton S, Myhre G, Osborne SR, Parker DJ, Rajot JL, Schulz M, Slingo A, Tanré D, Tulet P. 2008a.
Overview of the dust and biomass-burning experiment and African Monsoon Multidisciplinary Analysis Special Observing Period 0. J. Geophys. Res. 113: D00C17, DOI: 10.1029/2008JD010077.

Haywood JM, Bush M, Abel S, Claxton B, Coe H, Crosier J, Harrison M, Macpherson B, Naylor M, Osborne SR. 2008b. Prediction of visibility and aerosol within the operational Met Office Unified Model. II: Validation of model performance using observational data. Q. J. R. Meteorol. Soc. 134: 1817-1832.

Haywood JM, Johnson BT, Osborne SR, Baran AJ, Brooks M, Milton SF, Mulcahy J, Walters D, Allan RP, Woodage MJ, Klaver A, Formenti P, Brindley HE, Christopher S, Gupta P. 2011a. Motivation, rationale and key results from the GERBILS Saharan dust measurement campaign. Q. J. R. Meteorol. Soc. 137: 1106-1116, DOI: 10.1002/qj.797.

Haywood JM, Johnson BT, Osborne SR, Mulcahy J, Brooks M, Harrison MAJ, Milton SF, Brindley HE. 2011b. Observations and modelling of the solar and terrestrial radiative effects of Saharan dust: a radiative closure case-study over oceans during the GERBILS campaign. Q. J. R. Meteorol. Soc. 137: 1211-1226, DOI: 10.1002/qj.770.

Heintzenberg J. 2009. The SAMUM-1 experiment over southern Morocco: Overview and introduction. Tellus 61: 2-11.

Hesse E. 2008. Modelling diffraction during ray-tracing using the concept of energy flow lines. J. Quant. Spectrosc. Radiat. Transfer 109: $1374-1383$.

Highwood EJ, Haywood JM, Silverstone MD, Newman SM, Taylor JP. 2003. Radiative properties and direct effect of Saharan dust measured by the C-130 aircraft during SHADE. 2. Terrestrial spectrum. J. Geophys. Res. 108: 8578, DOI: 10.1029/2002JD002552.

Highwood EJ, Haywood JM, Coe H, Cook J, Osborne SR, Williams P, Crosier J, Bower K, Formenti P, McQuaid J, Brooks B, Thomas G, Grainger R, Barnaba F, Gobbi GP, de Leeuw G, Hopkins J. 2007. Aerosol Direct Radiative Impact Experiment (ADRIEX) overview. Q. J. R. Meteorol. Soc. 133: S1, 3-15.

Holben BN, Eck TF, Slutsker I, Tanré D, Buis JP, Setzer A, Vermote E, Reagan JA, Kaufman YJ, Nakajima T, Lavenu F, Jankowiak I, Smirnov A. 1998. AERONET - A federated instrument network and data archive for aerosol characterization. Remote Sens. Environ. 66: $1-16$.

Johnson BT, Osborne SR. 2011. Physical and optical properties of mineral dust aerosol measured by aircraft during the GERBILS campaign. Q. J. R. Meteorol. Soc. 137: 1117-1130, DOI: 10.1002/qj.777.

Kahnert M, Nousiainen T, Räisänen P. 2007. Mie simulations as an error source in mineral aerosol radiative forcing calculations. Q. J. $R$. Meteorol. Soc. 133: 299-307.

Kalashnikova OV, Sokolik IN. 2004. Modeling the radiative properties of nonspherical soil-derived mineral aerosols. J. Quant. Spectrosc. Radiat. Transfer 87: 137-166.

Klaver A, Formenti P, Caquineau S, Chevaillier S, Ausset P, Calzolai G, Osborne S, Johnson B, Harrison M, Dubovik O. 2011. Physicochemical and optical properties of Sahelian and Saharan mineral dust: in situ measurements during the GERBILS campaign. Q. J. R. Meteorol. Soc. 137: 1193-1210, DOI:10.1002/qj.889.

Kokhanovsky AA. 2003. Optical properties of irregularly shaped particles. J. Phys. D-Appl. Phys. 36: 915-923.

Lafon S, Sokolik IN, Rajot JL, Caquineau S, Gaudichet A 2006. Characterization of iron oxides in mineral dust aerosols: Implications for light absorption. J. Geophys. Res. 111: D21207, DOI: 10.1029/2005JD007016.

Legrand M, Plana-Fattori A, N'doumé C. 2001. Satellite detection of dust using the IR imagery of Meteosat 1 . Infrared difference dust index. J. Geophys. Res. 106: 18251-18274.

Macke A, Mueller J, Raschke E. 1996. Single scattering properties of atmospheric ice crystal. J. Atmos. Sci. 53: 2813-2825.

McConnell C, Highwood EJ, Coe H, Formenti P, Anderson B, Osborne SR, Nava S, Desbouefs K, Chen G, Harrison MAJ. 2008. Seasonal variations of the characteristics of optically important Saharan dust: Results from the Dust Outflow and Deposition to the Ocean (DODO) experiment. J. Geophys Res. 113: D14S05, DOI: 10.1029/2007JD009606.

McConnell C, Formenti P, Highwood EJ, Harrison MAJ. 2010. Using aircraft measurements to determine the refractive index of Saharan dust during the DODO experiments. Atmos. Chem. Phys. 10: 3081-3098.

Müller T, Schladitz A, Massling A, Kaaden N, Kandler K, Widensohler A. 2009. Spectral absorption coefficients and imaginary parts of refractive indices of Saharan dust during SAMUM-1. Tellus 61: 79-95.

Newman SM, Smith JA, Glew MD, Rogers SM, Taylor JP. 2005. Temperature and salinity dependence of sea surface emissivity in the thermal infrared. Q. J. R. Meteorol. Soc. 131: 2539-2557.

Nousiainen T. 2009. Optical modeling of mineral dust particles: A review. J. Quant. Spectrosc. Radiat. Transfer 110: 1261-1279, DOI 10.1016/j.jqsrt.2009.03.002. 
Osborne SR, Haywood JM, Francis PN, Dubovik O. 2004. Short-wave radiative effects of biomass burning aerosol during SAFARI2000. Q. J. R. Meteorol. Soc. 130: 1423-1447.

Osborne SR, Johnson BT, Haywood JM, Baran AJ, Harrison MAJ, McConnell CL. 2008. Physical and optical properties of mineral dust aerosol during the Dust and Biomass-burning Experiment. J. Geophys. Res. 113: D00C03, DOI: 10.1029/2007JD009551.

Otto S, de Reus M, Trautman T, Thomas A, Wendisch M, Borrmann S. 2007. Atmospheric radiative effects of an in situ measured Saharan dust plume and the role of large particles. Atmos. Chem. Phys. 7: 4887-4903.

Otto S, Bierwirth E, Weinzierl B, Kandler K, Esselborn M, Tesche M, Schladitz A, Wendisch M, Trautmann T. 2009. Solar radiative effects of a Saharan dust plume observed during SAMUM assuming spheroidal model particles. Tellus 61: 270-296.

Patterson EM, Gillette DA, Stockton BH. 1977. Complex index of refraction between 300 and $700 \mathrm{~nm}$ for Saharan aerosols. J. Geophys. Res. 82: 3153-3160.

Petzold A, Rasp K, Weinzierl B, Esselborn M, Hamburger T, Dornbrack A, Kandler K, Schütz L, Knippertz P, Fiebig M, Virkkula A. 2009. Saharan dust absoprtion and refractive index from aircraft-based observations during SAMUM 2006. Tellus B 61: 118-130.

Quijano A, Sokolik I, Toon OB. 2000. Radiative heating rates and direct radiative forcing by mineral dust in cloudy atmospheric conditions. J. Geophys. Res. 105(D10): 12207-12219.

Shenk WE, Curran RJ. 1974. The detection of dust storms over land and water with satellite visible and infrared measurements. Mon. Weather Rev. 102: 830-837.

Shettle EP, Fenn RW. 1979. 'Models for the aerosols for the lower atmosphere and the effects of humidity variations on their optical properties'. AFGL-TR-79-0214, Environmental Research Papers No. 676. Air Force Geophys. Lab: Hanscom, MA, USA.
Slingo A, Ackerman TP, Allan RP, Kassianov EI, McFarlane SA, Robinson GJ, Barnard JC, Miller MA, Harries JE, Russell JE, Dewitte S. 2006. Observations of the impact of a major Saharan dust storm on the atmospheric radiation balance. Geophys. Res. Lett. 33: L24817, DOI: 10.1029/2006GL027869A.

Sokolik I, Toon OB. 1999. Incoporation of mineralogical composition into models of the radiative properties of mineral aerosol from UV to IR wavelengths. J. Geophys. Res. 104: 9423-9444.

Volz FE. 1973. Infrared optical constants of ammonium sulfate, Sahara dust, volcanic pumice and flyash. Appl. Opt. 12: 755-759.

Weinzierl B, Petzold A, Esselborn M, Wirth M, Rasp K, Kandler K, Schutz L, Koepke P, Fiebig M. 2009. Airborne measurements of dust layer properties, particle size distribution and mixing state of Saharan dust during SAMUN 2006. Tellus B 61: 96-117.

Wendisch M, Coe H, Baumgardner D, Brenguier J-L, Dreiling V, Fiebig M, Formenti P, Hermann M, Krämer M, Levin Z, Maser R, Mathieu E, Nacass P, Noone K, Osborne SR, Schneider J, Schütz L, Schwarzenböck A, Stratmann F, Wilson JC. 2004. Supplement to aircraft particle inlets: State-of-the-art and future needs. Bull. Amer. Meteorol. Soc. 85: 92.

Wilson SHS, Atkinson NC, Smith JA. 1999. The development of an airborne infrared interferometer for meteorological sounding studies. J. Atmos. Oceanic Technol. 16: 1912-1927.

World Climate Program. 1986. A preliminary cloudless standard atmosphere for radiation computation. WMO/TD No. 24. (WCP report 112). World Meteorological Organization: Geneva.

Zhang J, Christopher SA. 2003. Long-Wave radiative forcing of Saharan dust aerosols estimated from MODIS, MISR, and CERES observations on Terra. Geophys. Res. Lett. 30: 2188, DOI: 10.1029/2003GL 0184479 . 